Supporting Information for

\title{
Conjugated Polymers in an Arene Sandwich
}

\author{
Anne J. McNeil, ${ }^{\dagger}$ Peter Müller, ${ }^{\dagger}$ James E. Whitten, ${ }^{\ddagger}$ and Timothy M. Swager ${ }^{*}{ }^{\dagger}$ \\ ${ }^{\dagger}$ Department of Chemistry, Massachusetts Institute of Technology, \\ 77 Massachusetts Ave, Cambridge, MA 02139, and ${ }^{\ddagger}$ Department of Chemistry \\ and Center for Advanced Materials, University of Massachusetts Lowell, One \\ University Avenue, Lowell, Massachusetts 01854
}

Contents

Page

Materials

S3

General Experimental

S3

Synthetic Procedures

Synthesis of P1

S5

Synthesis of $\mathbf{P 2}$

S8

Synthesis of $\mathbf{P} \mathbf{3}$

NMR Spectra

Figure S1. ${ }^{1} \mathrm{H}$ and ${ }^{13} \mathrm{C}$ NMR Spectra of S1b. $\quad \mathrm{S} 14$

Figure S2. ${ }^{1} \mathrm{H}$ and ${ }^{13} \mathrm{C}$ NMR Spectra of S1c. $\quad \mathrm{S} 15$

Figure S3. ${ }^{1} \mathrm{H}$ and ${ }^{13} \mathrm{C}$ NMR Spectra of S1d. $\quad \mathrm{S} 16$

Figure S4. ${ }^{1} \mathrm{H}$ NMR Spectrum of P1. $\quad \mathrm{S} 17$

Figure S5. ${ }^{1} \mathrm{H}$ and ${ }^{13} \mathrm{C}$ NMR Spectra of S2. $\quad \mathrm{S} 18$

Figure S6. ${ }^{1} \mathrm{H}$ and ${ }^{13} \mathrm{C}$ NMR Spectra of S2a. $\quad \mathbf{S 1 9}$

Figure S7. ${ }^{1} \mathrm{H}$ and ${ }^{13} \mathrm{C}$ NMR Spectra of S2b. $\quad S 20$

Figure S8. ${ }^{1} \mathrm{H}$ and ${ }^{13} \mathrm{C}$ NMR Spectra of S2c. $\quad$ S21

Figure S9. ${ }^{1} \mathrm{H}$ and ${ }^{13} \mathrm{C}$ NMR Spectra of S2d. $\quad$ S22

Figure S10. ${ }^{1} \mathrm{H}$ NMR Spectrum of P2. $\quad$ S23

Figure S11. ${ }^{1} \mathrm{H}$ and ${ }^{13} \mathrm{C}$ NMR Spectra of S3a. $\quad$ S24

Figure S12. ${ }^{1} \mathrm{H}$ and ${ }^{13} \mathrm{C}$ NMR Spectra of S3b. $\quad S 25$

Figure S13. ${ }^{1} \mathrm{H}$ and ${ }^{13} \mathrm{C}$ NMR Spectra of S3c. S26

Figure S14. ${ }^{1} \mathrm{H}$ and ${ }^{13} \mathrm{C}$ NMR Spectra of S3d. $\quad$ S27

Figure S15. ${ }^{1} \mathrm{H}$ NMR Spectrum of P3. S28 
X-ray Crystal Structures

Figure S16. Crystal Structure of S1b. $\quad$ S29

Figure S17. Crystal Structure of S2b. $\quad$ S30

Table S1. Summary of Bond Distances and Angles for S2b. S30

Figure S18. Crystal Structure of S3b. S31

Table S2. Summary of Bond Distances and Angles for S3b. S31

Figure S19. Crystal Structure of S3c. S32

Table S3. Summary of Bond Distances and Angles for S3c. S32

Electrochemistry

Figure S20. CV scans for S1b, S2b, and S3b $\quad$ S33

Table S4. Summary of Oxidation Potentials S33

Absorption and Emission Spectroscopy

Figure S21. Absorption Spectra for S1b, S2b, and S3b $\quad$ S34

Table S5. Summary of Spectral Data for Figure S21. S34

Figure S22. Absorption and Emission Spectra for P1, P2, P3 S35

Table S6. Summary of Spectral Data for Figure S22. $\quad$ S35

Figure S23. Solution Lifetime Data for P1, P2, P3 S36

Figure S24. Film Lifetime Data for P1, P2, P3 S36

Table S7. Summary of Lifetime Data for Figures S23-S24. S36

DFT Calculations

$\begin{array}{ll}\text { Figure S25. HOMO/LUMO Maps for S1b. } & \text { S37 }\end{array}$

Figure S26. HOMO/LUMO Maps for S2b. S38

Figure S27. HOMO/LUMO Maps for S3b. S39

Figure S28. HOMO/LUMO Maps for S2b-S2b. $\quad S 40$

Figure S29. HOMO/LUMO Maps for S1b-S1b. S41

Ultraviolet Photoelectron Spectroscopy

$\begin{array}{lr}\text { Figure S30. UPS Spectra for P2 and P3. S42 } & \text { S4 }\end{array}$

Table S8. Data for Figure S30. S42

Photobleaching Experiments

Figure S31. Relative Fluorescence Intensity versus Time S43

$\begin{array}{lr}\text { References } & \text { S44 }\end{array}$ 
Materials: Silica gel $(40 \mu \mathrm{m})$ was purchased from SiliCycle. All solvents used for photophysical experiments were spectral grade. 7-Tridecylamine was synthesized according to literature procedure. ${ }^{1}\left(\mathrm{Ph}_{3} \mathrm{P}\right)_{4} \mathrm{Pd}$ was purchased from Strem Chemicals, Inc. All other reagent grade materials were purchased from Aldrich, Lancaster, or Alfa Aesar, and used without further purification.

\section{Experimental:}

NMR Spectroscopy: ${ }^{1} \mathrm{H}$ and ${ }^{13} \mathrm{C}$ NMR spectra for all compounds were acquired in $\mathrm{CDCl}_{3}$ on a Bruker Avance Spectrometer operating at 400 and $100 \mathrm{MHz}$, respectively. The chemical shift data are reported in units of $\delta(\mathrm{ppm})$ relative to tetramethylsilane (TMS) and referenced with residual $\mathrm{CHCl}_{3}$.

Gel Permeation Chromatography (GPC): Polymer molecular weights were determined by comparison with polystyrene standards on a Hewlett Packard series 1100 HPLC instrument equipped with a Plgel $5 \mathrm{~mm}$ Mixed-C $(300 \times 7.5 \mathrm{~mm})$ column and analyzed with diode array (254 and $450 \mathrm{~nm}$ ) and refractive index detectors. Samples were dissolved in THF and passed through a $0.2 \mu \mathrm{m}$ PTFE filter prior to analysis.

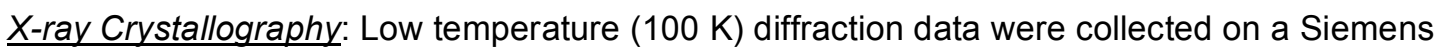
Platform three-circle diffractometer coupled to a Bruker-AXS Smart Apex CCD detector with graphite-monochromated Mo K $\alpha$ radiation $(\lambda=0.71073 \AA)$, performing $\varphi$ - and $\omega$-scans. All structures were solved by direct methods using SHELXS ${ }^{2}$ and refined against $F^{2}$ on all data by full-matrix least squares with SHELXL-97. ${ }^{3}$ All non-hydrogen atoms were refined anisotropically. The hydrogen atoms were included in the model at geometrically calculated positions and refined using a riding model. The isotropic displacement parameters of all hydrogen atoms were fixed to 1.2 times the $U$ value of the atoms they are linked to ( 1.5 times for methyl groups). Disorders in the structure of S3c (in the TIPS and $\mathrm{N}$-alkyl group) as well as in the solvent portion of S3b were refined with the help of similarity restraints on 1-2 and 1-3 distances and displacement parameters as well as rigid bond restraints for anisotropic displacement parameters and planarity restraints for the atoms involved. The occupancies of the disordered components were refined freely while constraining the total occupancy to unity.

Electrochemistry: The electrochemical studies were performed using an Autolab PGSTAT 20 potentiostat (Eco Chemie) in a three-electrode configuration. Cyclic voltammetry (CV) experiments were carried out in $\mathrm{CH}_{2} \mathrm{Cl}_{2}$ with $0.1 \mathrm{M}$ tetrabutylammonium hexafluorophosphate $\left(\mathrm{TBAPF}_{6}\right)$ as the supporting electrolyte. A glassy carbon button electrode $(3 \mathrm{~mm})$ was used as 
the working electrode and platinum wire served as the counter electrode. The potential was measured against $\mathrm{Ag} / \mathrm{AgNO}_{3}(10 \mathrm{mM})$. The potentials are reported versus an internal standard of ferrocene/ferricinium $\left(\mathrm{Fc} / \mathrm{Fc}^{+}\right)$couple with observed half-wave potentials between $250-300 \mathrm{mV}$.

\section{Absorption and Emission Spectroscopy: Fluorescence spectra were measured on a SPEX} Fluorolog- $\tau 3$ fluorometer (model FL-321, $450 \mathrm{~W}$ Xenon lamp) using either right-angle (solution) or front face (thin films) detection. Ultraviolet-visible absorption spectra were measured with an Agilent 8453 diode array spectrophotometer and corrected for background signal with a solventfilled cuvette or glass coverslip. Fluorescence quantum yields are determined relative to quinine sulfate and are corrected for solvent refractive index and absorption differences at the excitation wavelength.

Lifetime measurements: Time resolved fluorescence measurements were performed by exciting the samples with 160 femtosecond pulses at $390 \mathrm{~nm}$ from the double output of a Coherent RegA Ti:Sapphire amplifier. The resulting fluorescence was spectrally and temporally resolved with a Hamamatsu C4780 Streak Camera system.

Ultraviolet Photoelectron Spectroscopy: The UPS samples were prepared by spin-coating a $\mathrm{CHCl}_{3}$ solution (filtered first through basic alumina to remove acidic impurities) of the polymer (4 $\mathrm{mg} / \mathrm{mL}$ ) at $3000 \mathrm{rpm}$ onto gold substrates. The gold substrates were prepared by thermally depositing $2000 \AA$ of gold onto $\mathrm{Si}(111)$ wafers $\left(\sim 1 \mathrm{~cm}^{2}\right)$. Silver paste was used to make electrical contact with the polymer substrates. The UPS measurements were performed in a VG ESCALAB MKII photoelectron spectrometer having a base pressure of $1 \times 10^{-9} \mathrm{mbar}$. The excitation source was a differentially pumped He I lamp emitting $21.22 \mathrm{eV}$ radiation. The ejected photoelectrons were detected normal to the sample plane by a concentric hemispherical analyzer with a pass energy of $2 \mathrm{eV}$. The sample was biased relative to the ground $(-6.46 \mathrm{~V})$ to enable the low kinetic energy portion to be measured. The work function of the sample was calculated using the difference between the photon energy and the spectrum width. The width was determined by measuring the secondary electron cutoff on the low kinetic energy side of the spectrum and the edge of the HOMO on the high kinetic energy side. ${ }^{4}$

Photobleaching Experiments: Thin films of polymers P1-P3 were spin-coated from concentrated $\mathrm{CHCl}_{3}$ solutions onto glass coverslips to give homogeneous films with an $\mathrm{OD}=0.035 \pm 0.005$ at the excitation wavelength $(400 \mathrm{~nm})$. The polymer films were irradiated continuously for $30 \mathrm{~min}$ using our SPEX Fluorolog- $\tau 3$ fluorometer (model FL-321, $450 \mathrm{~W}$ Xenon lamp) with varying excitation slit widths $(2.5 \mathrm{~nm}, 5 \mathrm{~nm}, 15 \mathrm{~nm})$. Every $5 \mathrm{~min}$, the irradiation was stopped to acquire a fluorescence spectrum with front-face detection. The integrated area was recorded versus time. 


\section{Synthesis of P1}
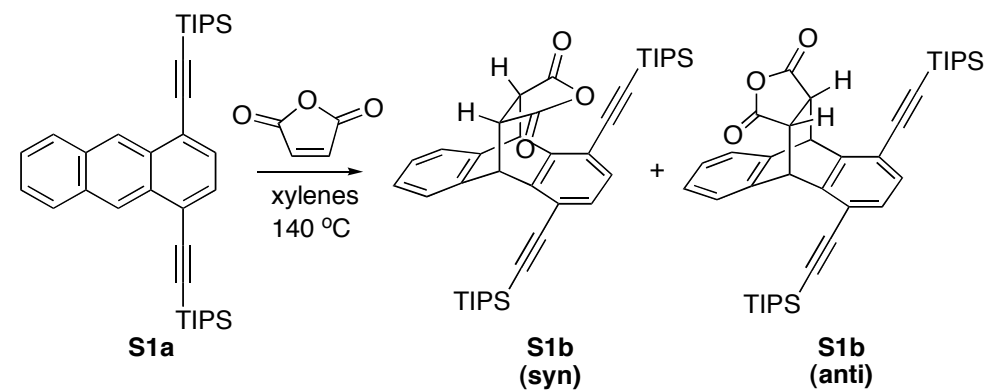

S1a was prepared from commercially available 1,4-anthraquinone according to literature procedure. $^{5}$

S1b: A $100 \mathrm{~mL}$ round-bottom flask was equipped with a stir bar, reflux condenser, and an argon inlet. Sequentially, $\mathbf{S} 1(0.35 \mathrm{~g}, 0.65 \mathrm{mmol})$, maleic anhydride $(0.64 \mathrm{~g}, 6.5 \mathrm{mmol})$ and xylenes (10 $\mathrm{mL}$ ) were added to the flask. The reaction mixture was heated to $140{ }^{\circ} \mathrm{C}$ overnight.

Dichloromethane was added to the reaction mixture and the resulting solution was concentrated in vacuo. ${ }^{1} \mathrm{H}$ NMR spectroscopy of the crude product mixture indicates a $\mathbf{S 1 b}(\mathbf{a n t i )}: \mathbf{S} 1 \mathbf{b}(\mathbf{s y n})$ ratio of $3.5: 1 .{ }^{6}$ Hexanes $(30 \mathrm{~mL})$ was added to the flask containing the crude product to dissolve mostly S1b(syn) and then decanted. The remaining solid residue was purified by column chromatography using 90/10 hexanes/EtOAc as the eluent gave $0.151 \mathrm{~g}$ of $\mathbf{S 1} \mathbf{b}(\mathbf{a n t i})$. The hexanes solution was concentrated in vacuo and purified by column chromatography with 90/10 hexanes/EtOAc to give $0.056 \mathrm{~g}$ of pure $\mathbf{S} \mathbf{b}$ (anti) and $0.020 \mathrm{~g}$ of pure $\mathbf{S} 1 \mathbf{b}(\mathbf{s y n})$. (The mixed fractions were discarded.) The total isolated material is $0.227 \mathrm{~g}$ (55\% yield). HRMS (ESI): Calcd. for $\mathrm{C}_{40} \mathrm{H}_{52} \mathrm{O}_{3} \mathrm{Si}_{2}, 637.3528[\mathrm{M}+\mathrm{H}]^{+}$; found, 637.3523. 

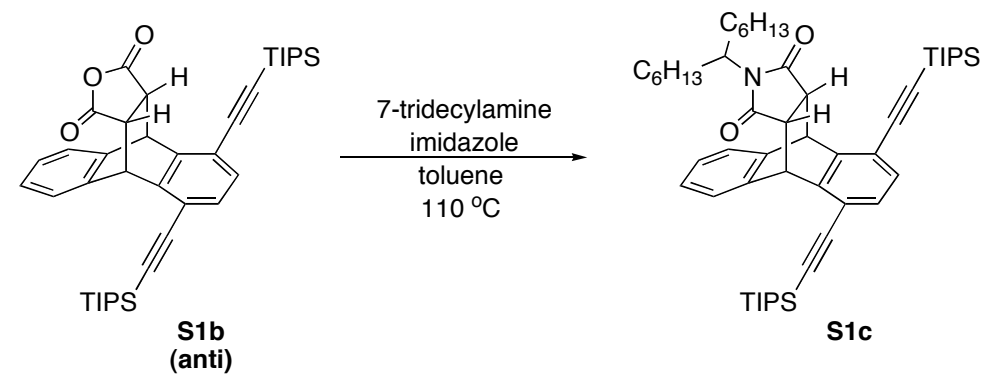

S1c: A $50 \mathrm{~mL}$ round-bottom flask was equipped with a stir bar, reflux condenser, and an argon inlet. Sequentially, S1b(anti) (207 mg, $0.325 \mathrm{mmol}$ ), 7-tridecylamine (78 mg, $0.39 \mathrm{mmol}$ ), imidazole $(33 \mathrm{mg}, 0.49 \mathrm{mmol})$ and toluene $(15 \mathrm{~mL})$ were added to the flask. The reaction mixture was heated to $110^{\circ} \mathrm{C}$ overnight. Ethyl acetate was then added and the resulting solution was concentrated in vacuo. Silica gel chromatography using 95/5 hexanes/EtOAc as the eluent gave $0.151 \mathrm{~g}$ of S1c (58\% yield). HRMS (ESI): Calcd. for $\mathrm{C}_{53} \mathrm{H}_{79} \mathrm{NO}_{2} \mathrm{Si}_{2}, 818.5722[\mathrm{M}+\mathrm{H}]^{+}$; found, 818.5759.
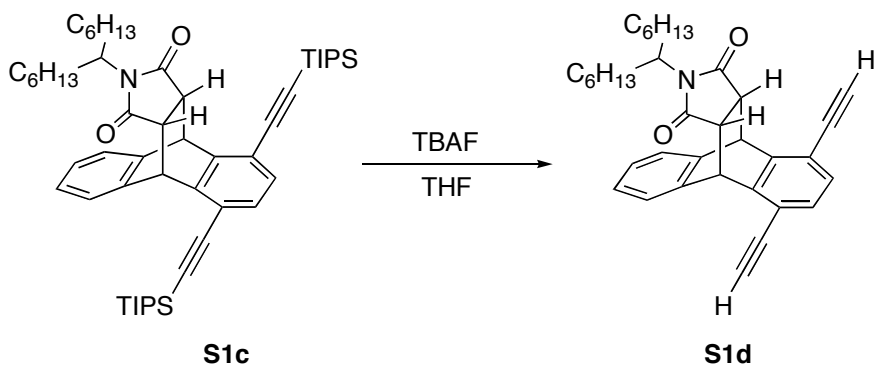

S1d: Into a $50 \mathrm{~mL}$ round bottom flask was added S1c (151 mg, $0.185 \mathrm{mmol})$, THF (15 mL), $\mathrm{H}_{2} \mathrm{O}$ $(0.1 \mathrm{~mL})$, and TBAF $(1.0 \mathrm{M}, 0.46 \mathrm{~mL})$. The reaction mixture is stirred at room temperature overnight. The homogeneous solution was then concentrated in vacuo. Silica gel chromatography using $95 / 5$ hexanes/EtOAc as the eluent gave $81 \mathrm{mg}$ of $\mathbf{S 1 d}$ ( $86 \%$ yield). HRMS (ESI): Calcd. for $\mathrm{C}_{35} \mathrm{H}_{39} \mathrm{NO}_{2}, 506.3054[\mathrm{M}+\mathrm{H}]^{+}$; found, 506.3063. 

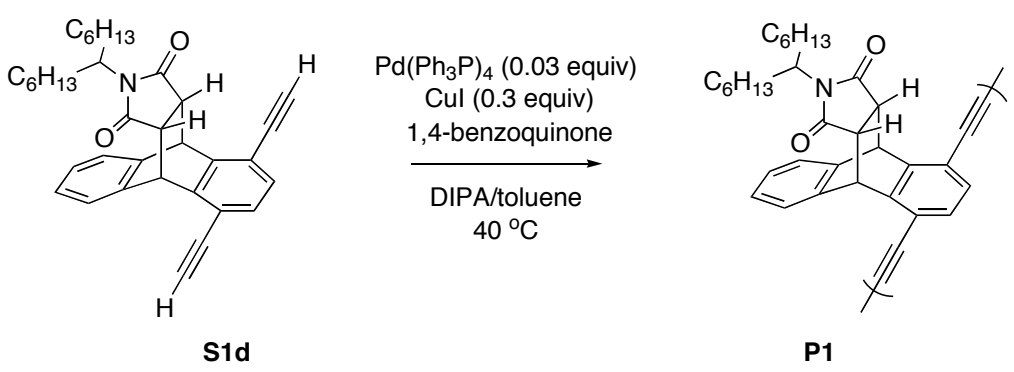

P1: 1,4-Benzoquinone (3.5 mg, 1.25 equiv), copper iodide (1.5 mg, 0.3 equiv), and tetrakis(triphenylphospine)palladium (1 $\mathrm{mg}, 0.03$ equiv) were added to a $75 \mathrm{~mL}$ Schlenk tube. The vessel was evacuated and refilled with Ar. Toluene $(2 \mathrm{~mL})$ and diisopropylamine $(1 \mathrm{~mL})$ were added to the tube. Lastly, a solution of $\mathbf{S 1 d}(13 \mathrm{mg})$ in toluene $(1 \mathrm{~mL})$ was added. The tube was sealed and heated to $40{ }^{\circ} \mathrm{C}$ overnight. Note that within approximately $10-15 \mathrm{~min}$, a brown gel-like material formed. THF was added and the mixture was precipitated into $\mathrm{MeOH}$. After centrifugation, the supernatent was removed. THF was added and the polymer solution was filtered through a short plug of silica. A copious amount of brown, insoluble polymer remained on the silica plug and yellow solution was obtained. GPC of the filtered solution indicates $M_{n}=64$ $\mathrm{kDa}, \mathrm{M}_{\mathrm{w}}=1600 \mathrm{kDa}, \mathrm{PDI}=2.6, \mathrm{DP}=127$. The polymer was further purified by concentrating the solution, dissolving the resulting material in $\mathrm{THF}$ or $\mathrm{CHCl}_{3}$, and then precipitating into $\mathrm{MeOH}$. IR (KCl) $1704 \mathrm{~cm}^{-1}$. 

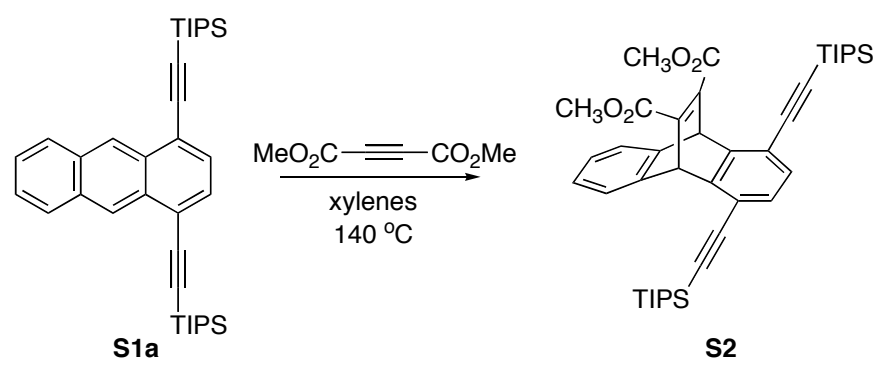

S2: In a $200 \mathrm{~mL}$ round-bottom flask was added S1a $(2.03 \mathrm{~g}, 4.0 \mathrm{mmol})$, dimethyl acetylenedicarboxylate $(3.6 \mathrm{~mL}, 40.0 \mathrm{mmol})$, and o-xylene $(40 \mathrm{~mL})$. The flask was equipped with a reflux condensor and the reaction was heated to $140{ }^{\circ} \mathrm{C}$ overnight under Ar. The product was purified by column chromatography using $90 / 10$ hexanes/EtOAc to give a sticky white solid that was washed with $\mathrm{MeOH}$ to remove the excess dimethyl acetylenedicarboxylate. After drying, 1.7 $\mathrm{g}$ of $\mathbf{S 2}$ was isolated (65\% yield). HRMS (ESI): Calcd. for $\mathrm{C}_{42} \mathrm{H}_{56} \mathrm{O}_{4} \mathrm{Si}_{2}, 681.3790[\mathrm{M}+\mathrm{H}]^{+}$; found, 681.3803.
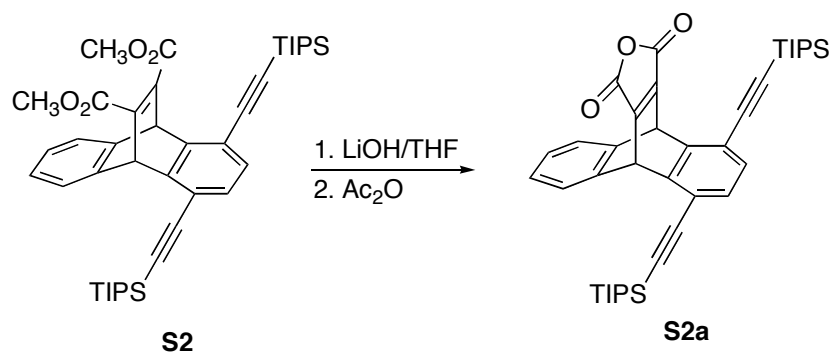

S2a: S2 $(1.3 \mathrm{~g}, 2.0 \mathrm{mmol})$ was placed in a $100 \mathrm{~mL}$ round-bottom flask with THF $(15 \mathrm{~mL})$ and $\mathrm{H}_{2} \mathrm{O}$ $(2 \mathrm{~mL})$. $\mathrm{LiOH}(0.5 \mathrm{~g}, 20 \mathrm{mmol})$ was added and the flask was capped and heated to $40{ }^{\circ} \mathrm{C}$ overnight. After cooling to room temperature, EtOAc and $\mathrm{H}_{2} \mathrm{O}$ were added. A $10 \% \mathrm{HCl}$ solution was added until the $\mathrm{pH}$ of the aqueous layer was acidic. The aqueous layer was extracted with EtOAc $(3 \times 75 \mathrm{~mL})$. The organic solutions were combined, dried over $\mathrm{MgSO}_{4}$ and filtered. The solution was concentrated to give a tacky, clear oil. Acetic anhydride $(\sim 80 \mathrm{~mL})$ was added and the flask was capped and heated to $60{ }^{\circ} \mathrm{C}$ overnight. After cooling to room temperature, toluene was added and the solvents were removed in vacuo. The product was purified by column chromatography using $50 / 50 \mathrm{CH}_{2} \mathrm{Cl}_{2} /$ hexanes to give $0.8 \mathrm{~g}$ of a clear, slightly yellow oil $(66 \%$ yield). HRMS (ESI): Calcd. for $\mathrm{C}_{40} \mathrm{H}_{50} \mathrm{O}_{3} \mathrm{Si}_{2}, 635.3371[\mathrm{M}+\mathrm{H}]^{+}$; found, 635.3390. 

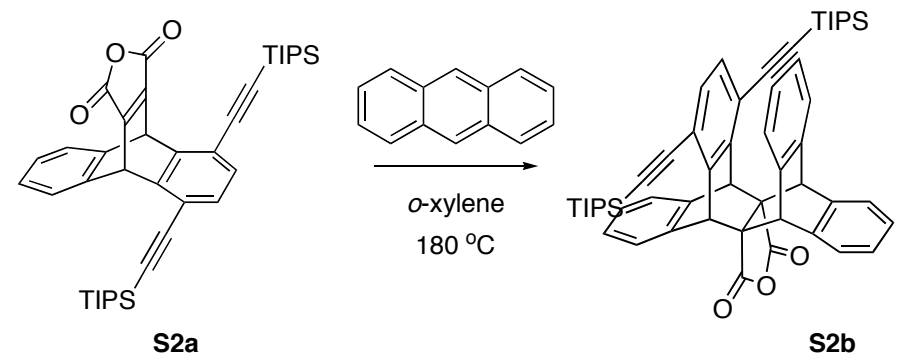

S2b: In a bomb flask was placed S2a $(0.41 \mathrm{~g}, 0.66 \mathrm{mmol})$, anthracene $(1.2 \mathrm{~g}, 6.7 \mathrm{mmol})$, and oxylene $(6 \mathrm{~mL})$ was added. The flask was sealed and the reaction was heated to $180^{\circ} \mathrm{C}$ overnight behind a blast shield. After cooling to room temperature, the product was purified by column chromatography using $30 / 70 \mathrm{CH}_{2} \mathrm{Cl}_{2}$ /hexanes to give $\mathbf{S 2 b}(0.342 \mathrm{~g}, 66 \%$ yield). HRMS (ESI): Calcd. for $\mathrm{C}_{54} \mathrm{H}_{60} \mathrm{O}_{3} \mathrm{Si}_{2}, 813.4154[\mathrm{M}+\mathrm{H}]^{+}$; found, 813.4132.
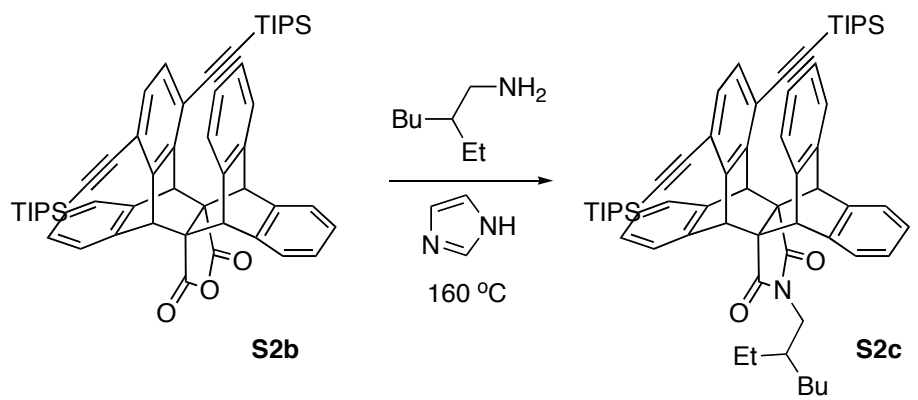

S2c: In a $50 \mathrm{~mL}$ round-bottom flask was placed S2b (342 $\mathrm{mg}, 0.44 \mathrm{mmol})$, imidazole (60 $\mathrm{mg}$, $0.87 \mathrm{mmol})$, and 2-ethyl-1-hexylamine $(\sim 10 \mathrm{~mL})$. The flask was equipped with a reflux condenser and $\mathrm{Ar}$ inlet and heated to $160^{\circ} \mathrm{C}$ overnight. After cooling to room temperature, EtOAc $(30 \mathrm{~mL})$ was added and the solution was extracted with $\mathrm{H}_{2} \mathrm{O}(50 \mathrm{~mL})$, aq. $\mathrm{NH}_{4} \mathrm{Cl}(50 \mathrm{~mL})$, and aq. $\mathrm{NaCl}(50 \mathrm{~mL})$. The organic layer was dried over $\mathrm{Na}_{2} \mathrm{SO}_{4}$, filtered and concentrated. Column chromatography using $20 / 80 \mathrm{CH}_{2} \mathrm{Cl}_{2} /$ hexanes gave $360 \mathrm{mg}$ of $\mathbf{S 2 c}$ (89\% yield). HRMS (ESI): Calcd. for $\mathrm{C}_{62} \mathrm{H}_{77} \mathrm{NO}_{2} \mathrm{Si}_{2}, 924.5566[\mathrm{M}+\mathrm{H}]^{+}$; found, 924.5578. 

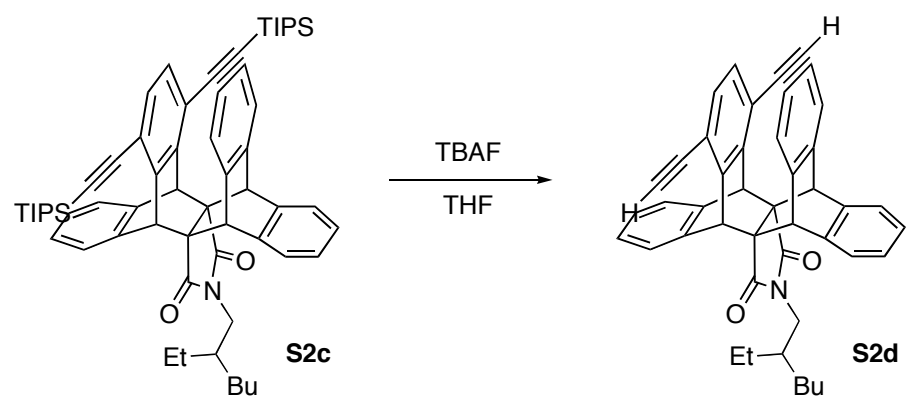

S2d: In a $50 \mathrm{~mL}$ round bottom flask was placed S2c (360 mg, $0.39 \mathrm{mmol})$, THF $(10 \mathrm{~mL})$, and $\mathrm{H}_{2} \mathrm{O}(0.1 \mathrm{~mL})$. TBAF (1.0 mL, 2.5 equiv) was added and the solution was stirred overnight. The reaction mixture was concentrated and the product was purified by column chromatography with 50/50 $\mathrm{CH}_{2} \mathrm{Cl}_{2} /$ hexanes to give S2d (192 mg, 81\% yield). IR (KCl) $1699 \mathrm{~cm}^{-1}$. HRMS (ESI): Calcd. for $\mathrm{C}_{44} \mathrm{H}_{37} \mathrm{NO}_{2}, 612.2897[\mathrm{M}+\mathrm{H}]^{+}$; found, 612.2906.
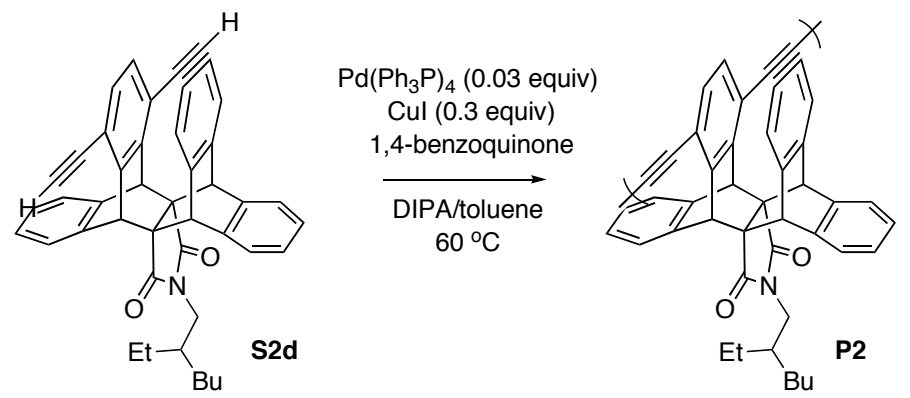

P2: 1,4-Benzoquinone (12.4 mg, 1.25 equiv), copper iodide (5.2 mg, 0.3 equiv), and tetrakis(triphenylphospine)palladium ( $3 \mathrm{mg}, 0.03$ equiv) were added to a $75 \mathrm{~mL}$ Schlenk tube. The vessel was evacuated and refilled with Ar. Toluene $(3 \mathrm{~mL})$ and diisopropylamine $(0.5 \mathrm{~mL})$ were added to the tube. Lastly, a solution of $\mathbf{S} 2 \mathbf{d}$ in toluene $(56 \mathrm{mg}, 1 \mathrm{~mL}$ ) was added and the tube was sealed and heated to $60{ }^{\circ} \mathrm{C}$ overnight. The reaction mixture was partitioned between $\mathrm{CHCl}_{3}$ and aq. $\mathrm{NH}_{4} \mathrm{Cl}$. The organic layer was extracted with aq. $\mathrm{NH}_{4} \mathrm{Cl}(3 \times 50 \mathrm{~mL})$ and subsequently dried over $\mathrm{MgSO}_{4}$. The yellow solution was concentrated to a film and then redissolved in approximately $1 \mathrm{~mL} \mathrm{CHCl}_{3}$. The polymer solution was then precipitated by dripping into $\mathrm{MeOH}$ and centrifuged. After removal of the supernatent, the polymer was subjected to soxhlet extractions with $\mathrm{MeOH}$, acetone, and $\mathrm{CHCl}_{3}$. The $\mathrm{CHCl}_{3}$ solution was again concentrated and the polymer was precipitated by dripping into $\mathrm{MeOH}$. GPC gave $\mathrm{M}_{\mathrm{n}}=58 \mathrm{kDa}, \mathrm{M}_{\mathrm{w}}=186 \mathrm{kDa}$, $\mathrm{PDI}=3.2, \mathrm{DP}=95 . \mathrm{IR}(\mathrm{KCl}) 1701 \mathrm{~cm}^{-1}$. 


\section{Synthesis of P3}

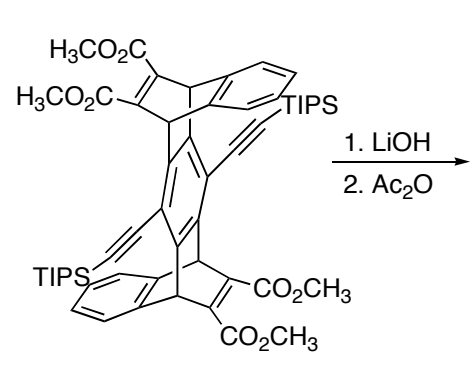

S3

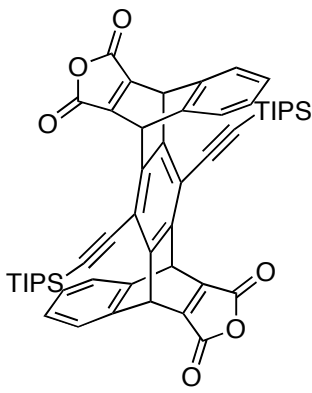

S3a

S3 was prepared from commercially available 6,13-pentacenequinone according to a literature procedure. $^{7}$

S3a: In a $50 \mathrm{~mL}$ round-bottom flask, S3 $(133 \mathrm{mg}, 0.14 \mathrm{mmol}$ ) was dissolved in THF (15 mL). $\mathrm{LiOH}\left(35 \mathrm{mg}, 1.4 \mathrm{mmol}\right.$ ) and $\mathrm{H}_{2} \mathrm{O}(2 \mathrm{~mL})$ were added and the flask was capped and heated to 40 ${ }^{\circ} \mathrm{C}$ overnight. The reaction mixture was partitioned between EtOAc/ $\mathrm{H}_{2} \mathrm{O}$ and an aq. $10 \% \mathrm{HCl}$ solution was added until the reaction mixture was acidic. The aqueous layer was extracted with EtOAc $(3 \times 50 \mathrm{~mL})$ and the organic layers were combined and dried over $\mathrm{MgSO}_{4}$. The solution was then concentrated to give a white solid. Acetic anhydride $(\sim 60 \mathrm{~mL})$ was added and the reaction was heated to $60{ }^{\circ} \mathrm{C}$ overnight. After cooling to room temperature, toluene $(\sim 30 \mathrm{~mL})$ was added and the solution was concentrated to give an off-white solid. The resulting solid was washed with hexanes to give $74 \mathrm{mg}$ of S3a (62\% yield). HRMS (ESI): Calcd. for $\mathrm{C}_{52} \mathrm{H}_{54} \mathrm{O}_{6} \mathrm{Si}_{2}$, $853.3351[\mathrm{M}+\mathrm{Na}]^{+}$; found, 853.3330 .
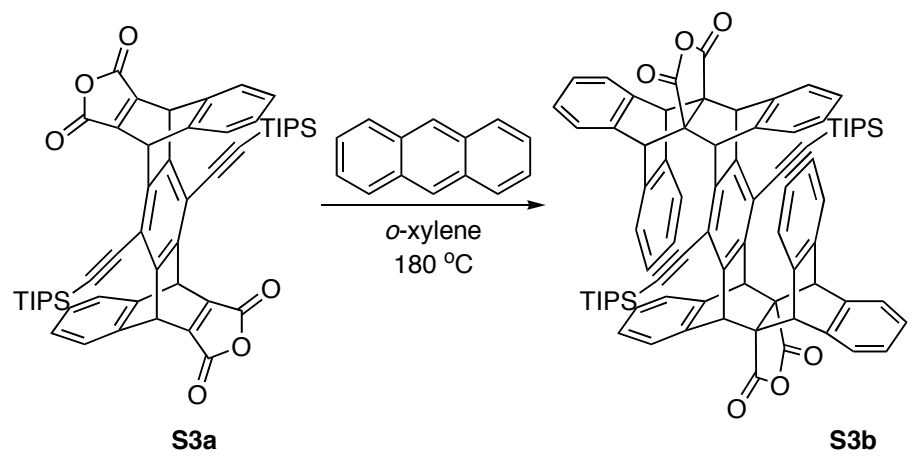

S3b: In a heavy-walled flask was placed S3a (74 mg, $0.09 \mathrm{mmol})$, anthracene (317 $\mathrm{mg}, 1.8$ $\mathrm{mmol})$, and o-xylene $(1 \mathrm{~mL})$. The flask was sealed and heated to $180{ }^{\circ} \mathrm{C}$ overnight. $\mathrm{CH}_{2} \mathrm{Cl}_{2}(50$ $\mathrm{mL}$ ) was added after cooling to room temperature and the solution was concentrated. Purification 
by column chromatography using $50 / 50 \mathrm{CH}_{2} \mathrm{Cl}_{2} /$ hexanes as the eluent gave a white solid ( $80 \mathrm{mg}$, $76 \%$ yield). HRMS (ESI): Calcd. for $\mathrm{C}_{80} \mathrm{H}_{74} \mathrm{O}_{6} \mathrm{Si}_{2}, 1187.5097[\mathrm{M}+\mathrm{H}]^{+}$; found, 1187.5071 .
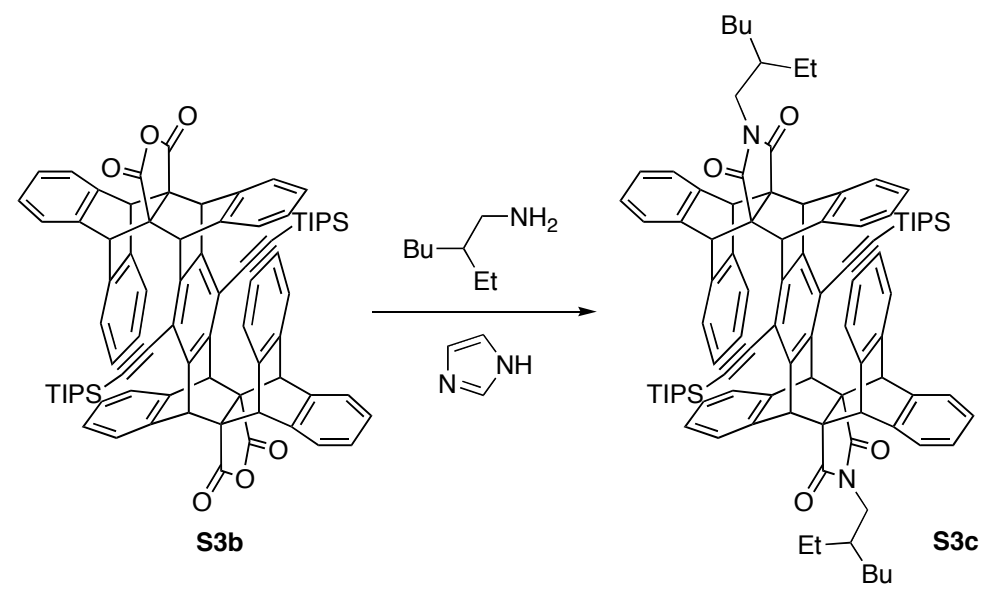

S3c: In a $50 \mathrm{~mL}$ round-bottom flask was placed S3b $(80 \mathrm{mg}, 0.067 \mathrm{mmol})$, imidazole $(1 \mathrm{~g})$, and 2ethyl-1-hexylamine ( 8 $\mathrm{mL})$. The flask was equipped with a reflux condenser and Ar inlet and heated to $160{ }^{\circ} \mathrm{C}$ overnight. The reaction mixture became homogeneous after heating for several hours. After cooling to room temperature, EtOAc $(30 \mathrm{~mL})$ was added and the solution was concentrated in vacuo. Column chromatography using $50 / 50 \mathrm{CH}_{2} \mathrm{Cl}_{2} /$ hexanes gave $81 \mathrm{mg}$ of S3C (86\% yield). HRMS (ESI): Calcd. for $\mathrm{C}_{96} \mathrm{H}_{108} \mathrm{~N}_{2} \mathrm{O}_{4} \mathrm{Si}_{2}, 1409.7920[\mathrm{M}+\mathrm{H}]^{+}$; found, 1409.7892.
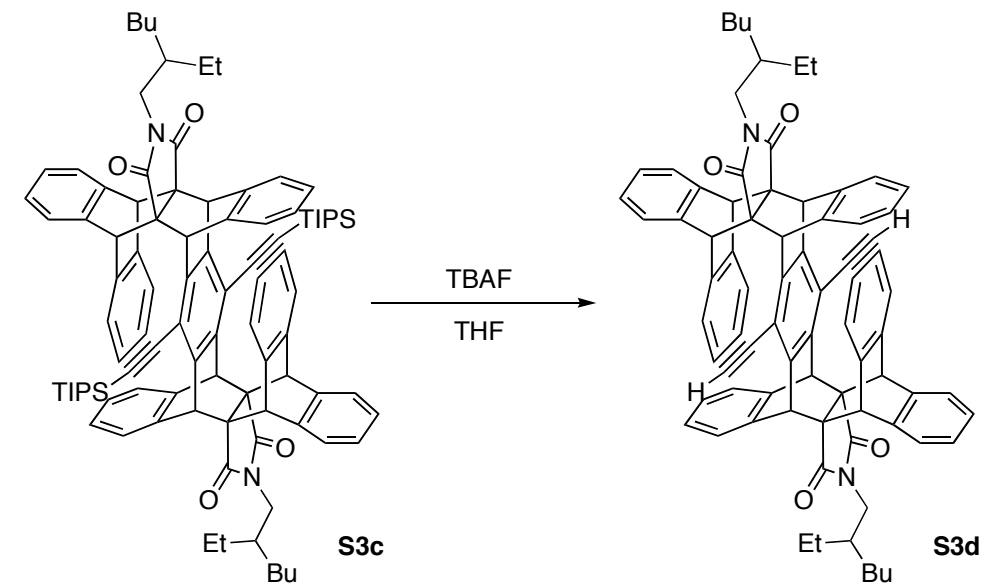

S3d: In a $20 \mathrm{~mL}$ vial was placed S3c $(50 \mathrm{mg}, 0.035 \mathrm{mmol})$, THF $(10 \mathrm{~mL})$, and $\mathrm{H}_{2} \mathrm{O}(0.1 \mathrm{~mL})$. An excess of TBAF ( $>2$ equiv) was added and the solution was stirred overnight. The reaction mixture was concentrated and the product was purified by column chromatography with $50 / 50$ 
$\mathrm{CH}_{2} \mathrm{Cl}_{2} /$ hexanes as the eluent. The column was flushed with EtOAc and this solution was combined with the product fractions. Concentrating the combined solutions gave $\mathbf{S} \mathbf{d} \mathbf{d}$ as a white solid (36 mg, 92\% yield). The product can be further purified by crystallization from $95 / 5$ $\mathrm{CH}_{3} \mathrm{CN} /$ benzene $(\sim 1-2 \mathrm{~mL}$ ) with heating and slow solvent evaporation. HRMS (ESI): Calcd. for $\mathrm{C}_{78} \mathrm{H}_{68} \mathrm{~N}_{2} \mathrm{O}_{4}, 1097.5252[\mathrm{M}+\mathrm{H}]^{+}$; found, 1097.5271.
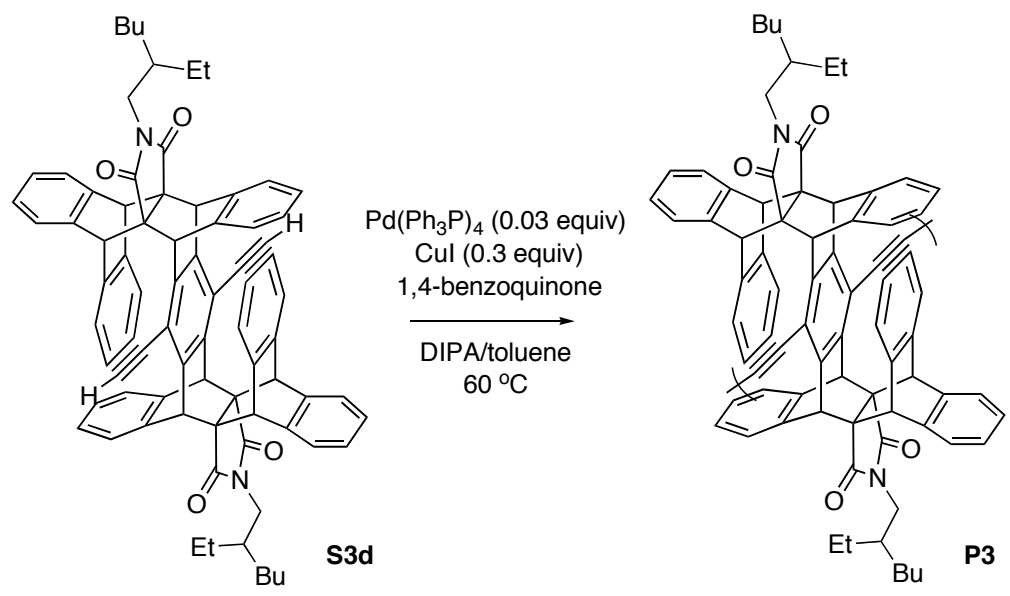

P3: 1,4-Benzoquinone (3 mg, 1.25 equiv), copper iodide (1.3 mg, 0.3 equiv), and S3d (24 mg, $0.022 \mathrm{mmol}$ ) were added to a $75 \mathrm{~mL}$ Schlenk tube. The vessel was evacuated and refilled with Ar. Toluene $(3 \mathrm{~mL})$ and diisopropylamine $(1 \mathrm{~mL})$ were added to the tube. Lastly, tetrakis(triphenylphospine)palladium ( $0.6 \mathrm{mg}, 0.03$ equiv) was added and the tube was sealed and heated to $60{ }^{\circ} \mathrm{C}$ for $48 \mathrm{~h}$. The reaction mixture was partitioned between $\mathrm{CHCl}_{3}$ and aq. $\mathrm{NH}_{4} \mathrm{Cl}$. The organic layer was extracted with aq. $\mathrm{NH}_{4} \mathrm{Cl}(3 \times 50 \mathrm{~mL})$ and subsequently dried over $\mathrm{MgSO}_{4}$. The yellow solution was concentrated and then redissolved in approximately $0.5 \mathrm{~mL}$ $\mathrm{CHCl}_{3}$. The polymer solution was then precipitated by dripping into $\mathrm{MeOH}$ and centrifuged. The polymer was redissolved in $0.5 \mathrm{~mL} \mathrm{CHCl}$ and precipitated by dripping into $\mathrm{MeOH}$ to give $10 \mathrm{mg}$ of a yellow powder (42\% yield). GPC gave $M_{n}=17,000, M_{w}=38,000$ PDI $=2.2, D P=16$. 


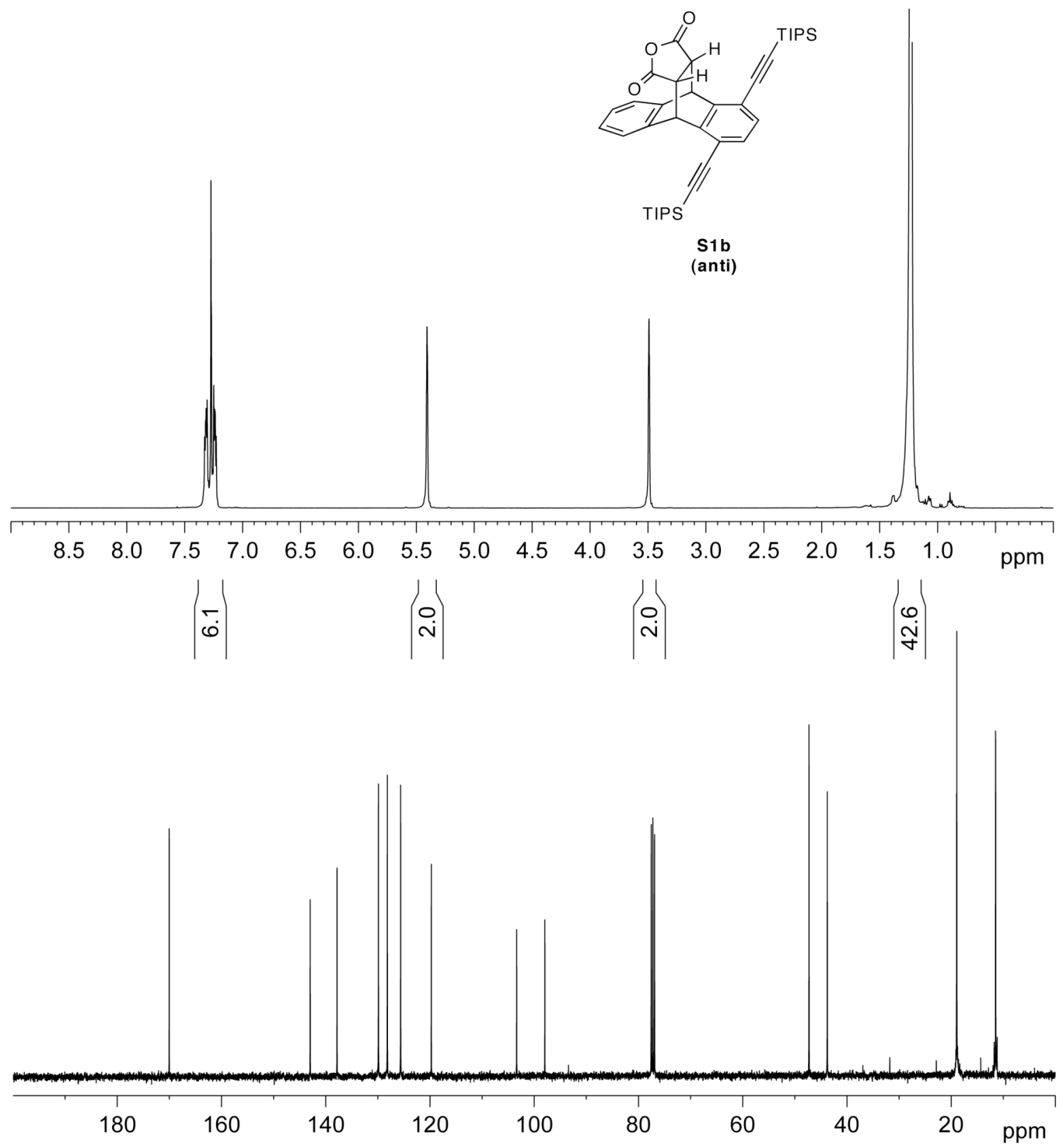

Figure S1. ${ }^{1} \mathrm{H}$ and ${ }^{13} \mathrm{C}$ NMR Spectra of $\mathbf{S} 1 \mathrm{~b}\left(\right.$ anti). ${ }^{1} \mathrm{H}$ NMR $\left(400 \mathrm{MHz}, \mathrm{CDCl}_{3}\right) \delta 7.32(\mathrm{~m}, 2 \mathrm{H})$, $7.27(\mathrm{~s}, 2 \mathrm{H}), 7.24(\mathrm{~m}, 2 \mathrm{H}), 5.41(\mathrm{~s}, 2 \mathrm{H}), 3.49(\mathrm{~s}, 2 \mathrm{H}), 1.23(\mathrm{~s}, 42 \mathrm{H}) .{ }^{13} \mathrm{C} \mathrm{NMR}\left(100 \mathrm{MHz}, \mathrm{CDCl}_{3}\right) \delta$ 170.02, 142.97, 137.82, 129.88, 128.17, 125.62, 119.73, 103.37, 97.97, 47.29, 43.78, 18.95, 11.48 . 


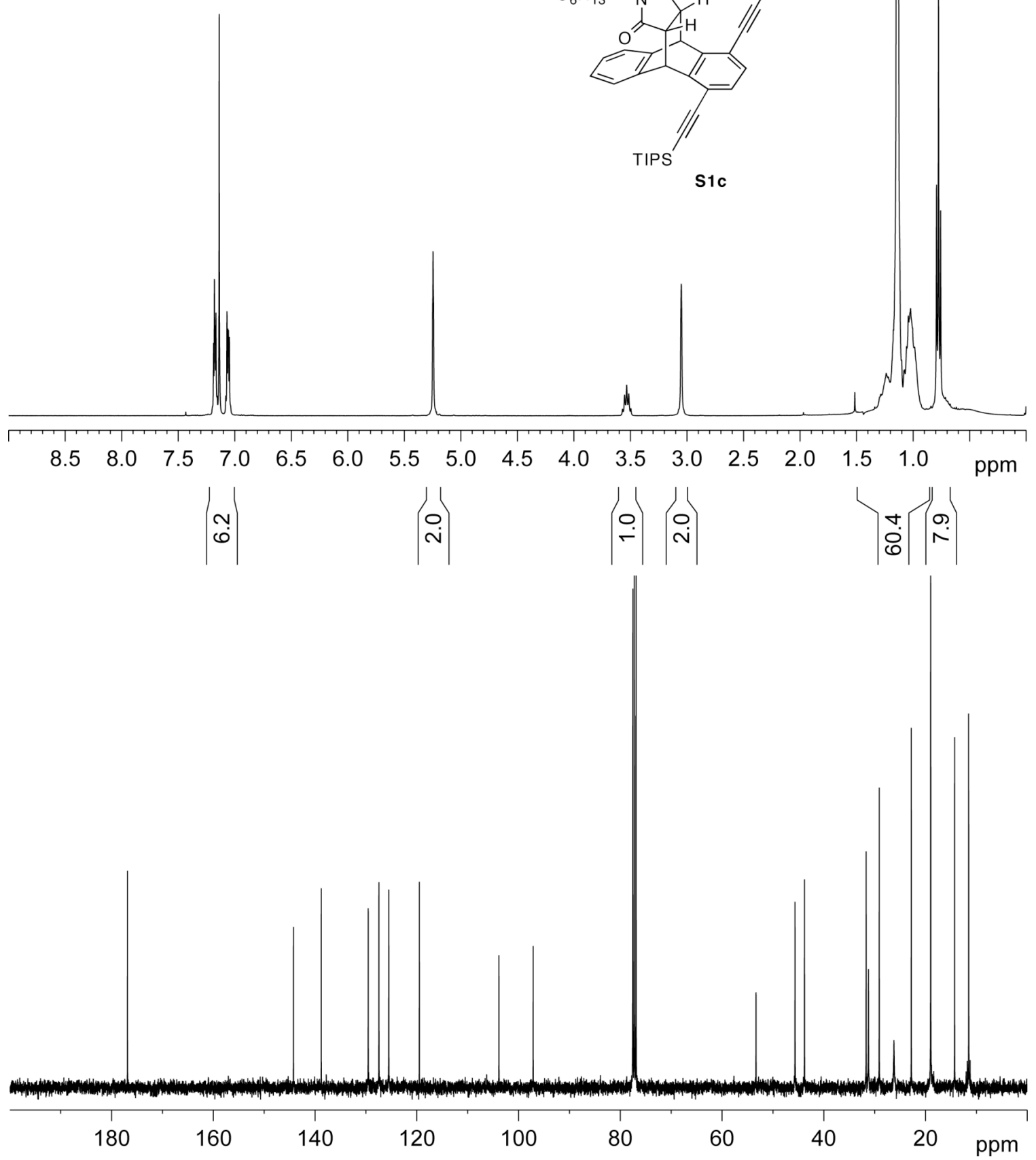

Figure S2. ${ }^{1} \mathrm{H}$ and ${ }^{13} \mathrm{C}$ NMR Spectra of S1c. ${ }^{1} \mathrm{H}$ NMR $\left(400 \mathrm{MHz}, \mathrm{CDCl}_{3}\right) \delta 7.17(\mathrm{~m}, 2 \mathrm{H}), 7.13(\mathrm{~s}$, $2 \mathrm{H}$ ), $7.06(\mathrm{~m}, 2 \mathrm{H}), 5.25(\mathrm{~s}, 2 \mathrm{H}), 3.53$ (quin, $J=7.2 \mathrm{~Hz}, 1 \mathrm{H}), 3.05(\mathrm{~s}, 2 \mathrm{H}), 1.5-0.9(\mathrm{~m}, 62 \mathrm{H}), 0.78(\mathrm{t}$, $J=6.8 \mathrm{~Hz}, 6 \mathrm{H}) .{ }^{13} \mathrm{C} \mathrm{NMR}\left(100 \mathrm{MHz}, \mathrm{CDCl}_{3}\right) \delta 176.86,144.24,138.77,129.55,127.44,125.50$, $119.49,103.84,97.13,53.33,45.66,43.80,31.68,31.23,29.11,26.22,22.80,18.99,14.28$, 11.52 . 


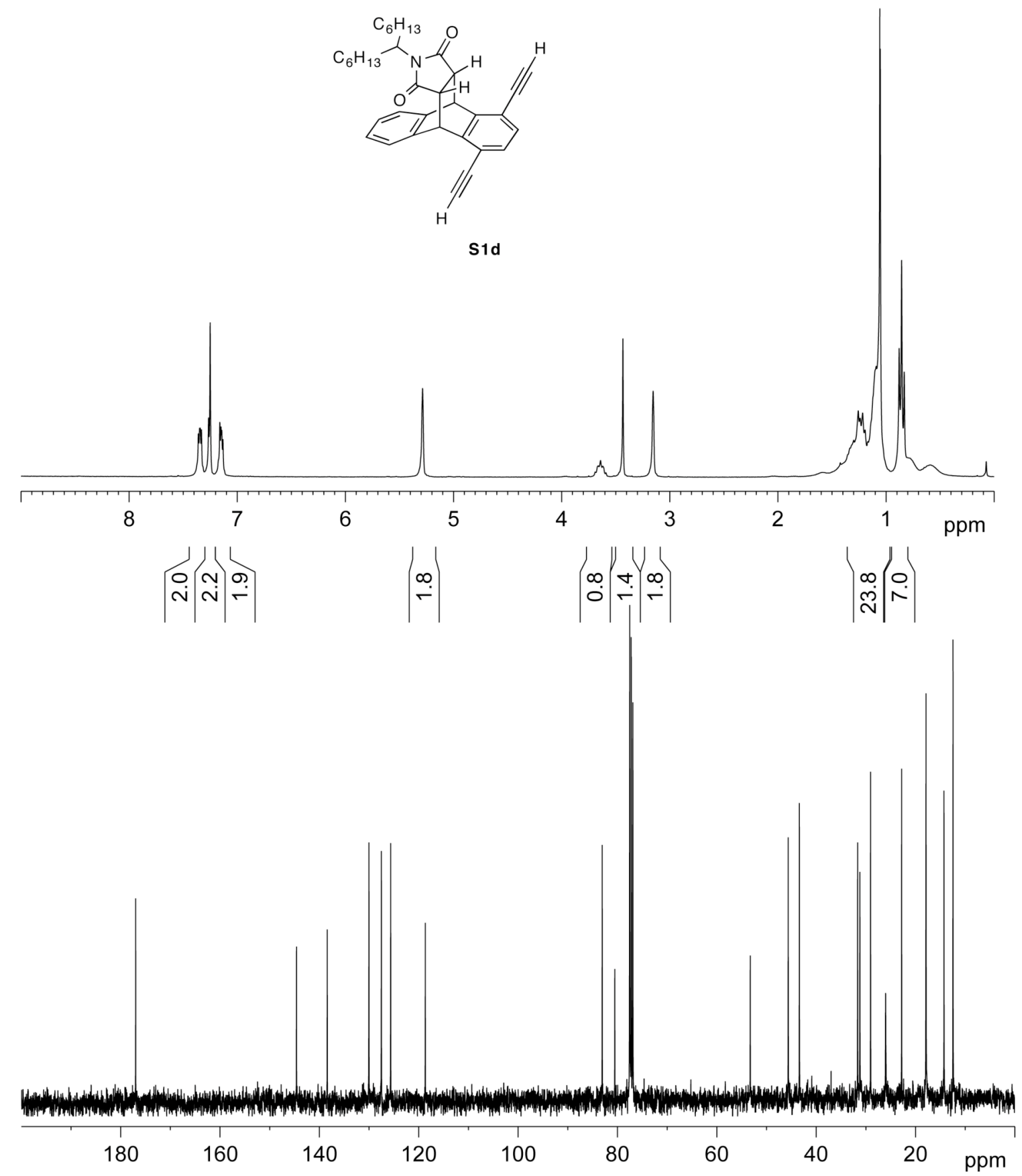

Figure S3. ${ }^{1} \mathrm{H}$ and ${ }^{13} \mathrm{C}$ NMR Spectra of S1d. ${ }^{1} \mathrm{H}$ NMR $\left(400 \mathrm{MHz}, \mathrm{CDCl}_{3}\right) \delta 7.34(\mathrm{~m}, 2 \mathrm{H}), 7.24(\mathrm{~s}$, $2 \mathrm{H}$ ), $7.15(\mathrm{~m}, 2 \mathrm{H}), 5.29(\mathrm{~s}, 2 \mathrm{H}), 3.63$ (quin, $J=7.6 \mathrm{~Hz}, 1 \mathrm{H}), 3.45(\mathrm{~s}, 2 \mathrm{H}), 3.16(\mathrm{~s}, 2 \mathrm{H}), 1.3-0.9(\mathrm{~m}$, $20 \mathrm{H}), 0.86(\mathrm{t}, J=7.6 \mathrm{~Hz}, 6 \mathrm{H}) .{ }^{13} \mathrm{C}$ NMR $\left(100 \mathrm{MHz}, \mathrm{CDCl}_{3}\right) \delta 176.98,144.60,138.42,130.02$, $127.52,125.65,118.67,83.06,80.53,53.27,45.62,43.38,31.66,31.21,29.05,26.02,22.79$, 14.27. 


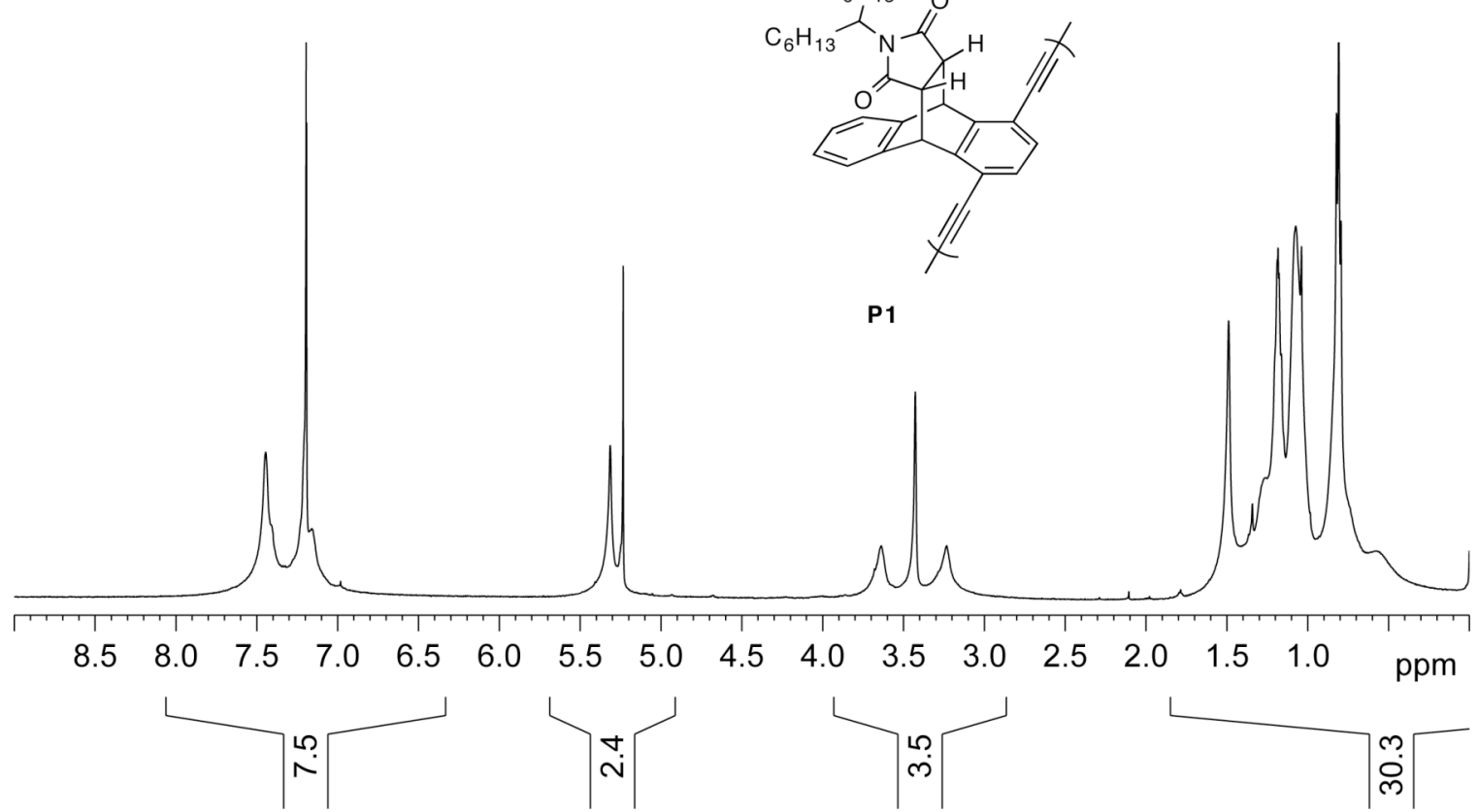

Figure S4. ${ }^{1} \mathrm{H}$ NMR Spectrum of P1. ${ }^{1} \mathrm{H}$ NMR $\left(400 \mathrm{MHz}, \mathrm{CDCl}_{3}\right) \delta 7.44(\mathrm{bm}, 2 \mathrm{H}), 7.19(\mathrm{~s}, 2 \mathrm{H})$, 7.18 (bm, 2H), 5.31 (bs, 2H), 3.64 (bm, 1H), 3.23 (bs, 2H), 1.4-0.8 (bm, 26H). 


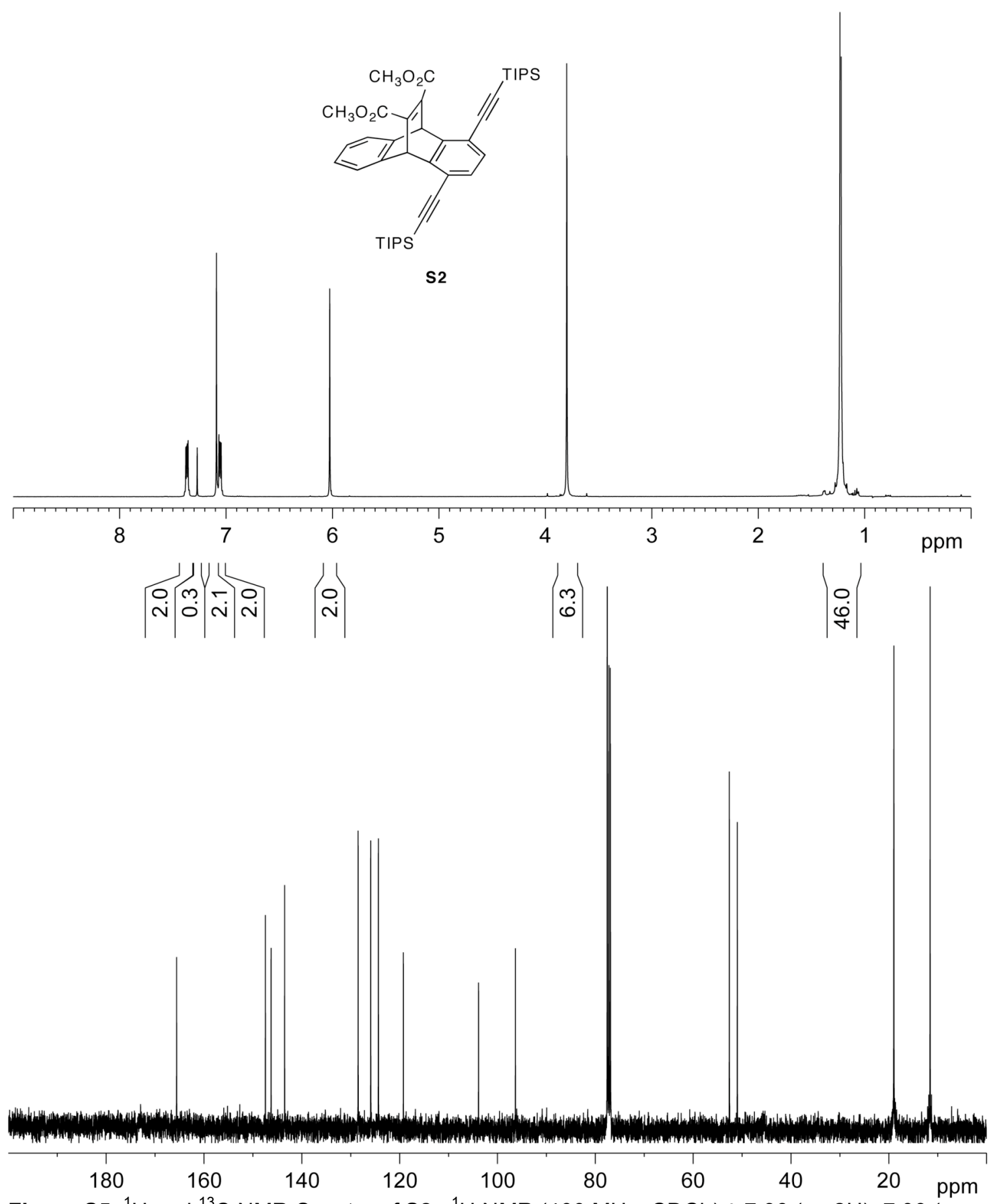

Figure S5. ${ }^{1} \mathrm{H}$ and ${ }^{13} \mathrm{C}$ NMR Spectra of S2. ${ }^{1} \mathrm{H}$ NMR $\left(400 \mathrm{MHz}, \mathrm{CDCl}_{3}\right) \delta 7.36(\mathrm{~m}, 2 \mathrm{H}), 7.09(\mathrm{~s}$, $2 \mathrm{H}), 7.06(\mathrm{~m}, 2 \mathrm{H}), 6.03(\mathrm{~s}, 2 \mathrm{H}), 3.80(\mathrm{~s}, 6 \mathrm{H}), 1.23(\mathrm{~s}, 42 \mathrm{H}) .{ }^{13} \mathrm{C} \mathrm{NMR}\left(100 \mathrm{MHz}, \mathrm{CDCl}_{3}\right) \delta 165.59$, $147.43,146.28,143.50,128.48,125.89,124.33,119.22$, 103.86, 96.32, 52.60, 50.96, 18.96, 11.55. 


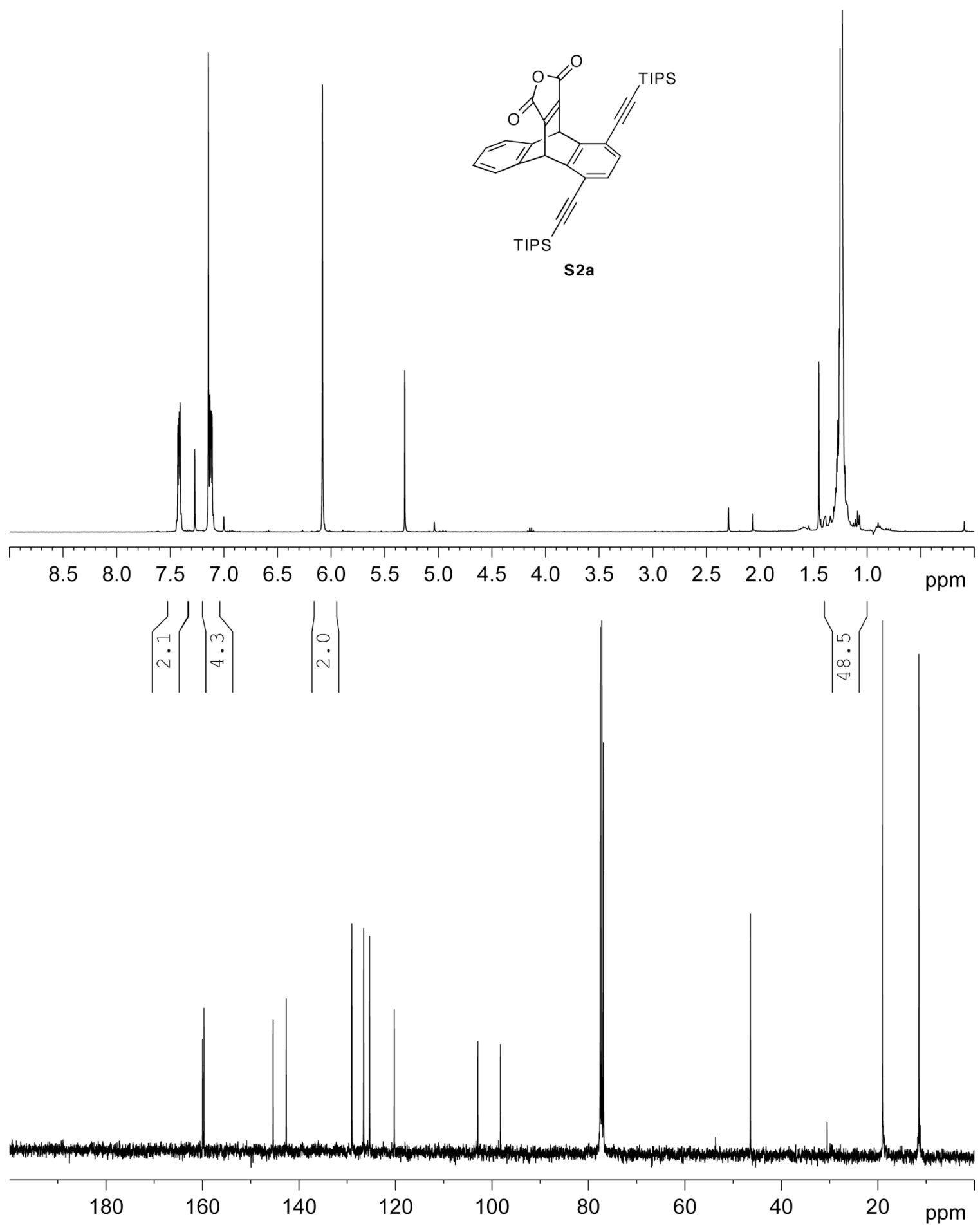

Figure S6. ${ }^{1} \mathrm{H}$ and ${ }^{13} \mathrm{C}$ NMR Spectra of S2a. ${ }^{1} \mathrm{H}$ NMR $\left(400 \mathrm{MHz}, \mathrm{CDCl}_{3}\right) \delta 7.42(\mathrm{~m}, 2 \mathrm{H}), 7.14(\mathrm{~s}$, $2 \mathrm{H}), 7.12(\mathrm{~m}, 2 \mathrm{H}), 6.08(\mathrm{~s}, 2 \mathrm{H}), 1.26(\mathrm{~s}, 42 \mathrm{H}) .{ }^{13} \mathrm{C}$ NMR $\left(100 \mathrm{MHz}, \mathrm{CDCl}_{3}\right) \delta$ 159.97, 159.68, 145.34, 142.62, 129.02, 126.58, 125.35, 120.24, 102.91, 98.22, 46.22, 18.96, 11.49. 


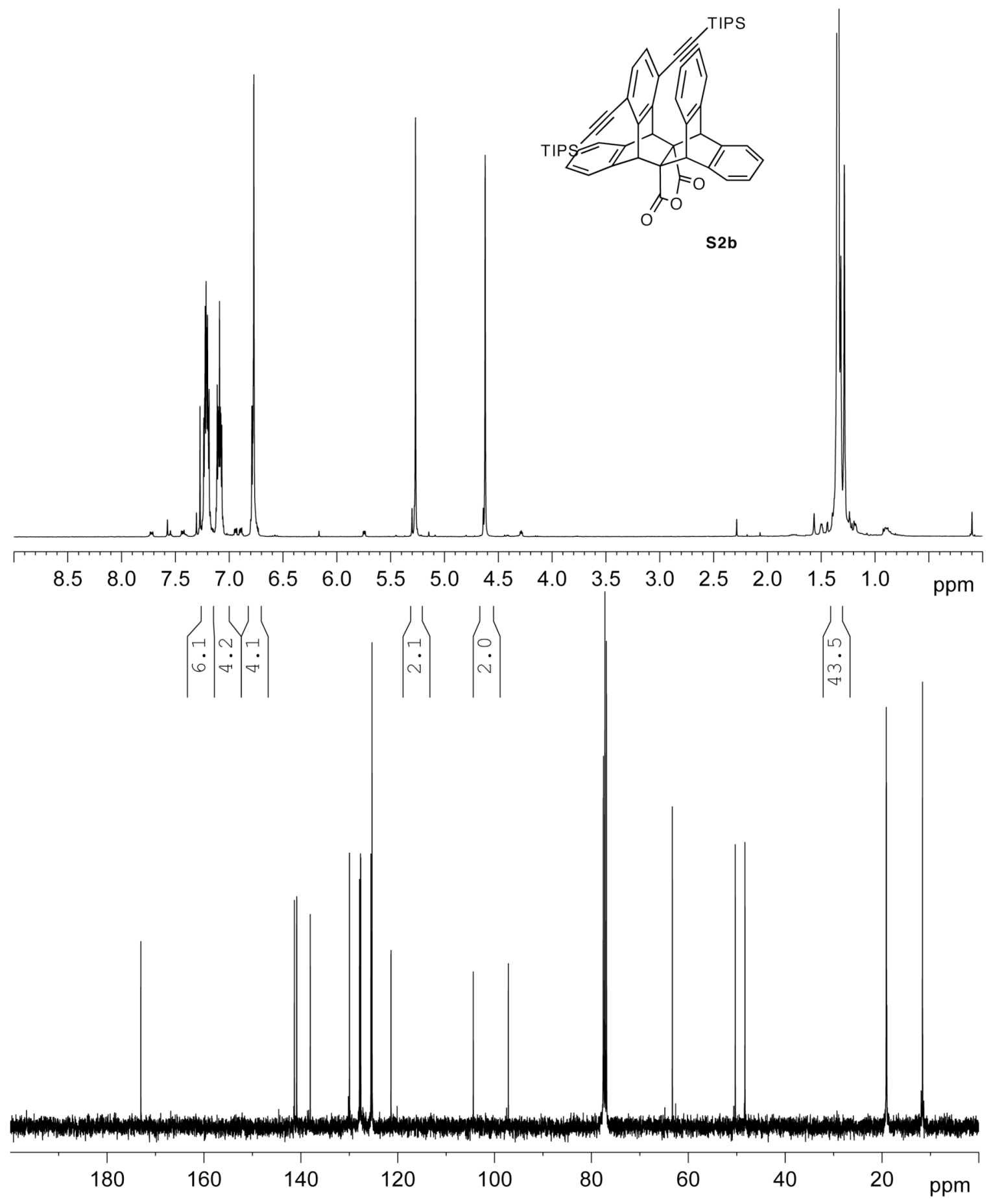

Figure S7. ${ }^{1} \mathrm{H}$ and ${ }^{13} \mathrm{C}$ NMR Spectra of S2b. ${ }^{1} \mathrm{H}$ NMR $\left(400 \mathrm{MHz}, \mathrm{CDCl}_{3}\right) \delta 7.21(\mathrm{~m}, 6 \mathrm{H}), 7.09(\mathrm{~m}$, $4 \mathrm{H}), 6.78(\mathrm{~m}, 4 \mathrm{H}), 5.27(\mathrm{~s}, 2 \mathrm{H}), 4.62(\mathrm{~s}, 2 \mathrm{H}), 1.35(\mathrm{~s}, 42 \mathrm{H}) .{ }^{13} \mathrm{C} \mathrm{NMR}\left(100 \mathrm{MHz}, \mathrm{CDCl}_{3}\right) \delta 173.03$, $141.33,140.85,140.82,138.04,129.94,127.87,127.67,127.62,125.52,125.29,121.37,104.38$, $97.14,63.28,50.29,48.29,19.12,11.64$. 


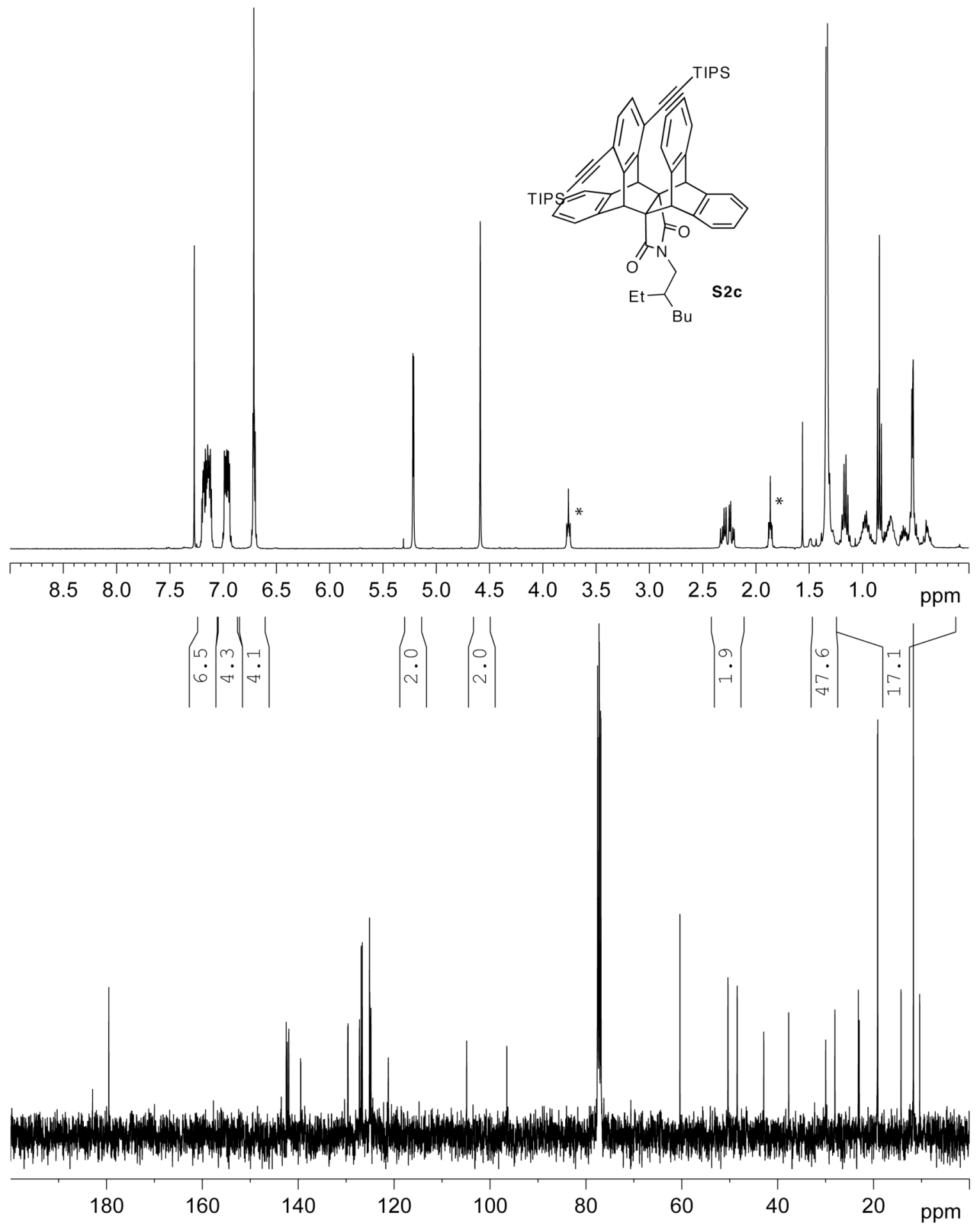

Figure S8. ${ }^{1} \mathrm{H}$ and ${ }^{13} \mathrm{C}$ NMR Spectra of S2c. ${ }^{1} \mathrm{H}$ NMR $\left(400 \mathrm{MHz}, \mathrm{CDCl}_{3}\right) \delta 7.15(\mathrm{~m}, 6 \mathrm{H}), 6.95(\mathrm{~m}$, $4 \mathrm{H}), 6.72(\mathrm{~s}, 2 \mathrm{H}), 6.70(\mathrm{~m}, 2 \mathrm{H}), 5.22(\mathrm{~s}, 2 \mathrm{H}), 4.58(\mathrm{~s}, 2 \mathrm{H}), 2.25(\mathrm{~m}, 2 \mathrm{H}), 1.56(\mathrm{~s}, 42 \mathrm{H}), 1.33-0.84$ $(\mathrm{m}, 15 \mathrm{H}) .{ }^{13} \mathrm{C}$ NMR $\left(100 \mathrm{MHz}, \mathrm{CDCl}_{3}\right) \delta 179.50,142.50,142.26,141.95,139.51$ (d), 129.63 (d), 127.23 (d), 126.86, 126.62, 125.12, 125.06, 124.87 (d), 121.19, 104.87, 96.48, 60.39, 50.38, $48.44,42.90,37.70,29.98,28.06,23.19,23.00,19.15,14.27,11.69,10.38$. *Denotes THF contamination. 

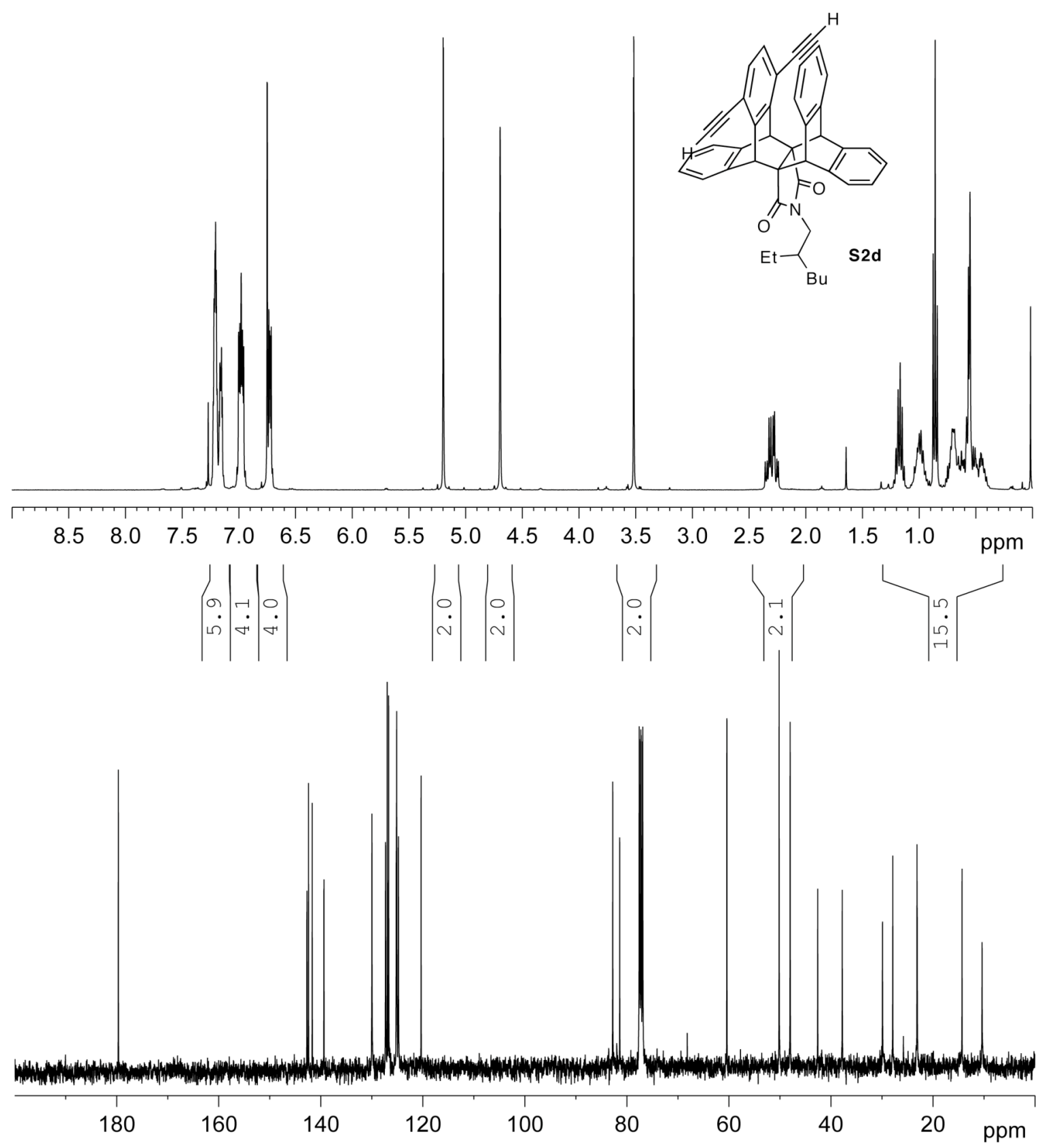

Figure S9. ${ }^{1} \mathrm{H}$ and ${ }^{13} \mathrm{C}$ NMR Spectra of S2d. ${ }^{1} \mathrm{H}$ NMR (400 MHz, CDCl 3$) \delta 7.21(\mathrm{~m}, 4 \mathrm{H}), 7.15(\mathrm{~m}$, $2 \mathrm{H}), 6.97(\mathrm{~m}, 4 \mathrm{H}), 6.75(\mathrm{~s}, 2 \mathrm{H}), 6.72(\mathrm{~m}, 2 \mathrm{H}), 5.20(\mathrm{~s}, 2 \mathrm{H}), 4.70(\mathrm{~s}, 2 \mathrm{H}), 3.52(\mathrm{~s}, 2 \mathrm{H}), 2.30(\mathrm{~m}$, $2 \mathrm{H}), 1.18-0.55(\mathrm{~m}, 15 \mathrm{H}) .{ }^{13} \mathrm{C} N M R\left(100 \mathrm{MHz}, \mathrm{CDCl}_{3}\right) \delta$ 179.67, 142.71 (d), 142.39, 141.66, 139.38 (d), 129.97, 127.30, 126.97, 126.69, 125.18 (d), 125.12, 124.78 (d), 120.33, 82.77, 81.40, $60.42,50.16,48.01,42.60,37.79,29.91,27.90,23.14,23.09,14.32,10.39$. 


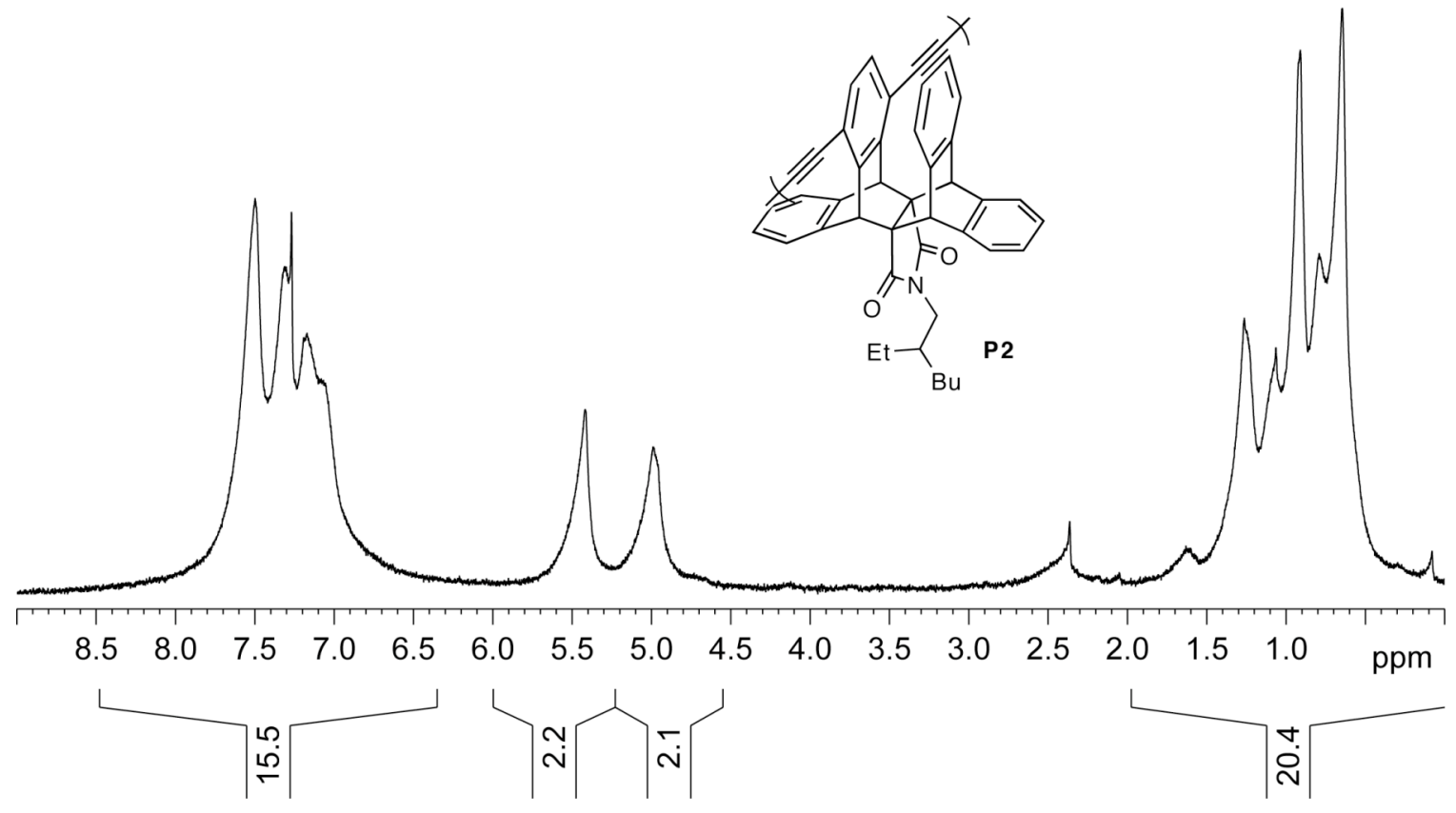

Figure S10. ${ }^{1} \mathrm{H}$ NMR Spectrum of P2. ${ }^{1} \mathrm{H}$ NMR $\left(400 \mathrm{MHz}, \mathrm{CDCl}_{3}\right) \delta 7.50(\mathrm{bm}, 6 \mathrm{H}), 7.31(\mathrm{bm}$, 4H), 7.17 (bm, 2H), 7.06 (bm, 2H), 5.42 (bs, 2H), 4.99 (bs, 2H), 2.36 (bm, 2H), 1.27-0.65 (m, $15 \mathrm{H})$. 


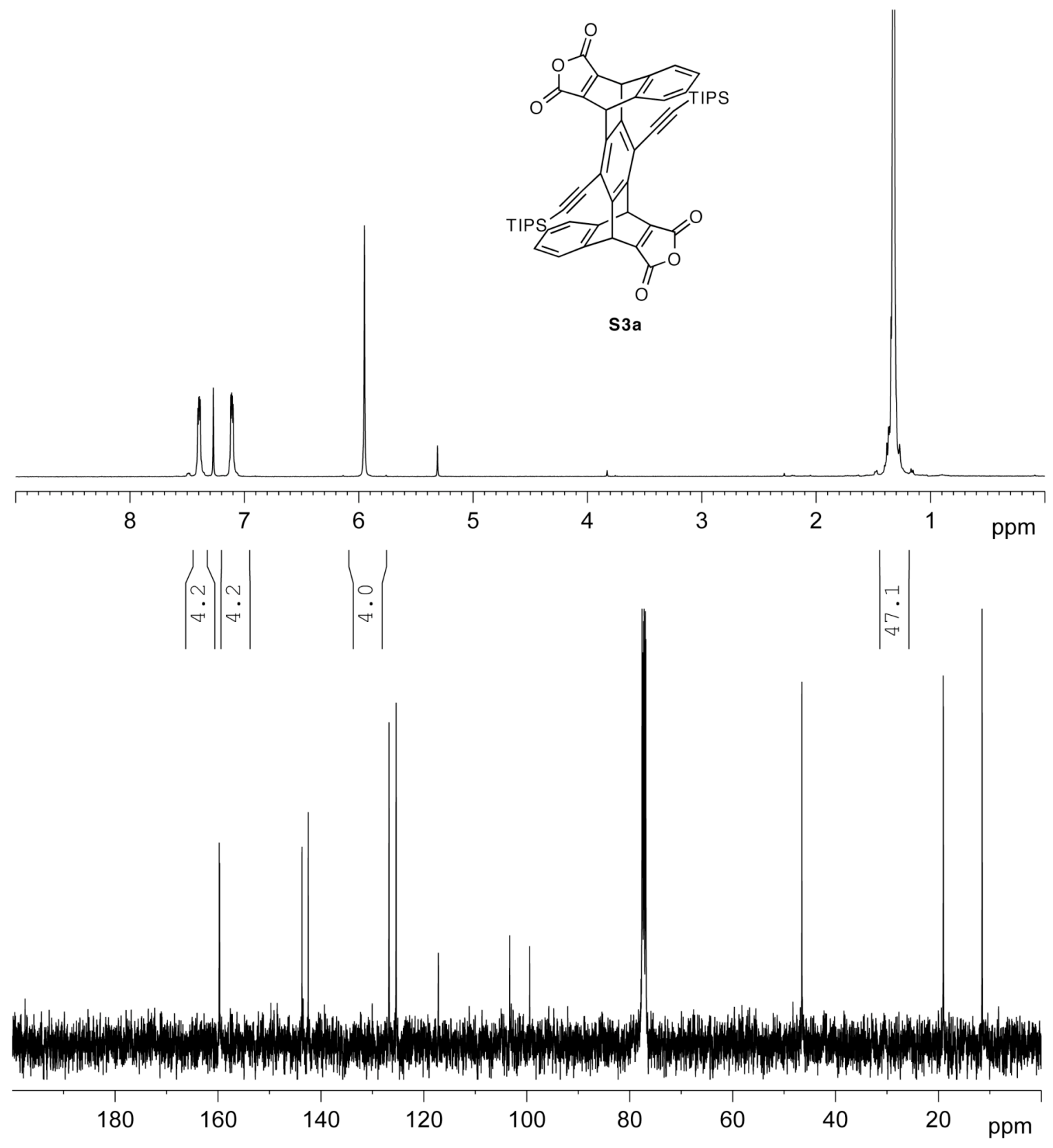

Figure S11. ${ }^{1} \mathrm{H}$ and ${ }^{13} \mathrm{C}$ NMR Spectra of S3a. ${ }^{1} \mathrm{H}$ NMR $\left(400 \mathrm{MHz}, \mathrm{CDCl}_{3}\right) \delta 7.40(\mathrm{~m}, 4 \mathrm{H}), 7.10$ $(\mathrm{m}, 4 \mathrm{H}), 5.95(\mathrm{~s}, 4 \mathrm{H}), 1.34(\mathrm{~s}, 42 \mathrm{H}) .{ }^{13} \mathrm{C}$ NMR $\left(100 \mathrm{MHz}, \mathrm{CDCl}_{3}\right) \delta$ 159.77, 159.69, 143.69, 142.47, 126.77, 125.39, 117.19, 103.32, 99.43, 46.56, 19.05, 11.52. 


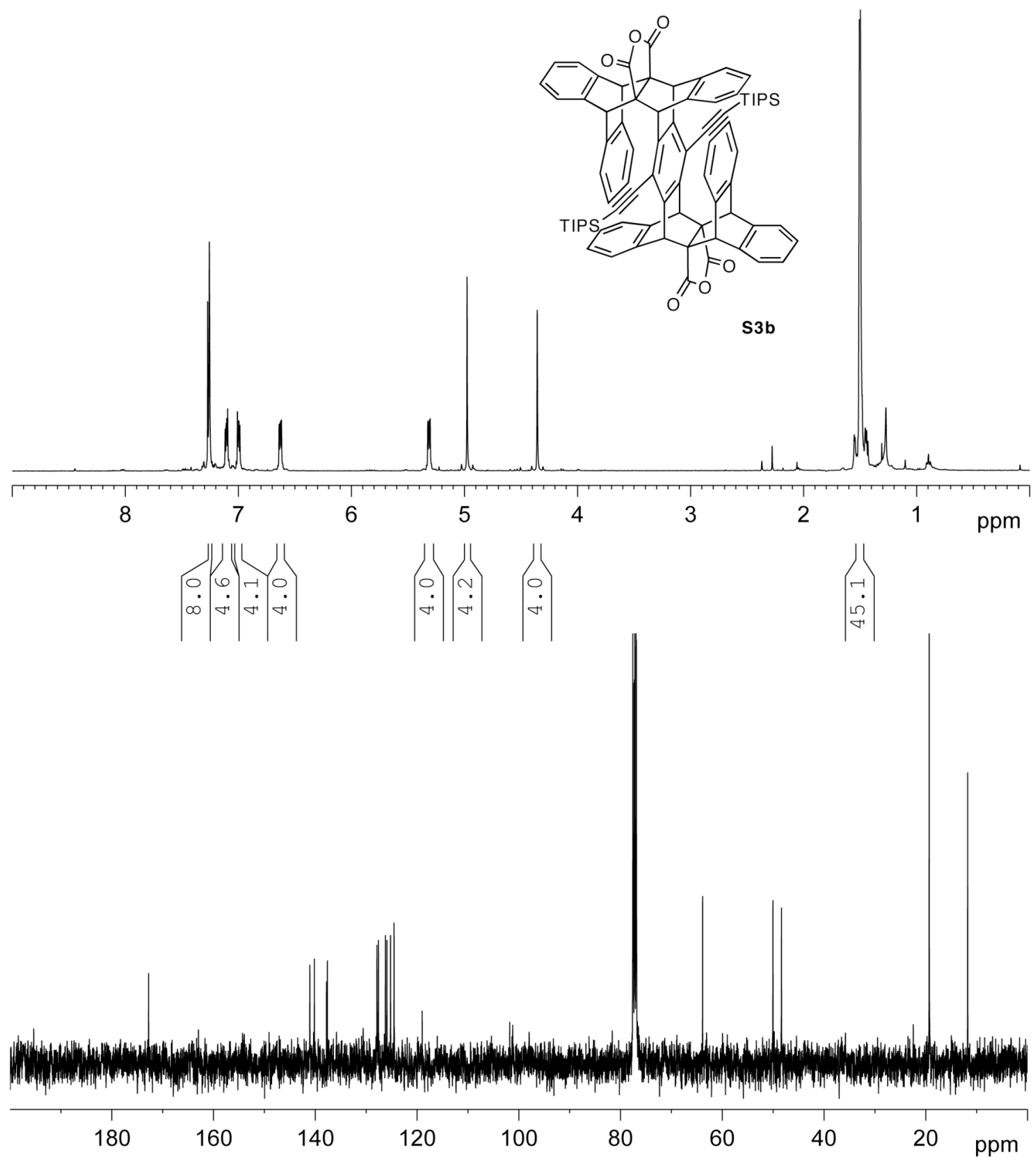

Figure S12. ${ }^{1} \mathrm{H}$ and ${ }^{13} \mathrm{C}$ NMR Spectra of S3b. ${ }^{1} \mathrm{H}$ NMR $\left(400 \mathrm{MHz}, \mathrm{CDCl}_{3}\right) \delta 7.26(\mathrm{~m}, 8 \mathrm{H}), 7.10$ $(\mathrm{m}, 4 \mathrm{H}), 7.00(\mathrm{~m}, 4 \mathrm{H}), 6.61(\mathrm{~m}, 4 \mathrm{H}), 5.32(\mathrm{~m}, 4 \mathrm{H}), 5.31(\mathrm{~s}, 4 \mathrm{H}), 4.36(\mathrm{~s}, 4 \mathrm{H}), 1.50(\mathrm{~s}, 42 \mathrm{H}) .{ }^{13} \mathrm{C}$ $\operatorname{NMR}\left(100 \mathrm{MHz}, \mathrm{CDCl}_{3}\right) \delta 172.76,141.07,140.18,137.80,137.62,127.88,127.58,126.22$, $125.92,125.21,124.52,118.98,101.77,101.99,63.86,50.05,48.37,19.33,11.76$. 


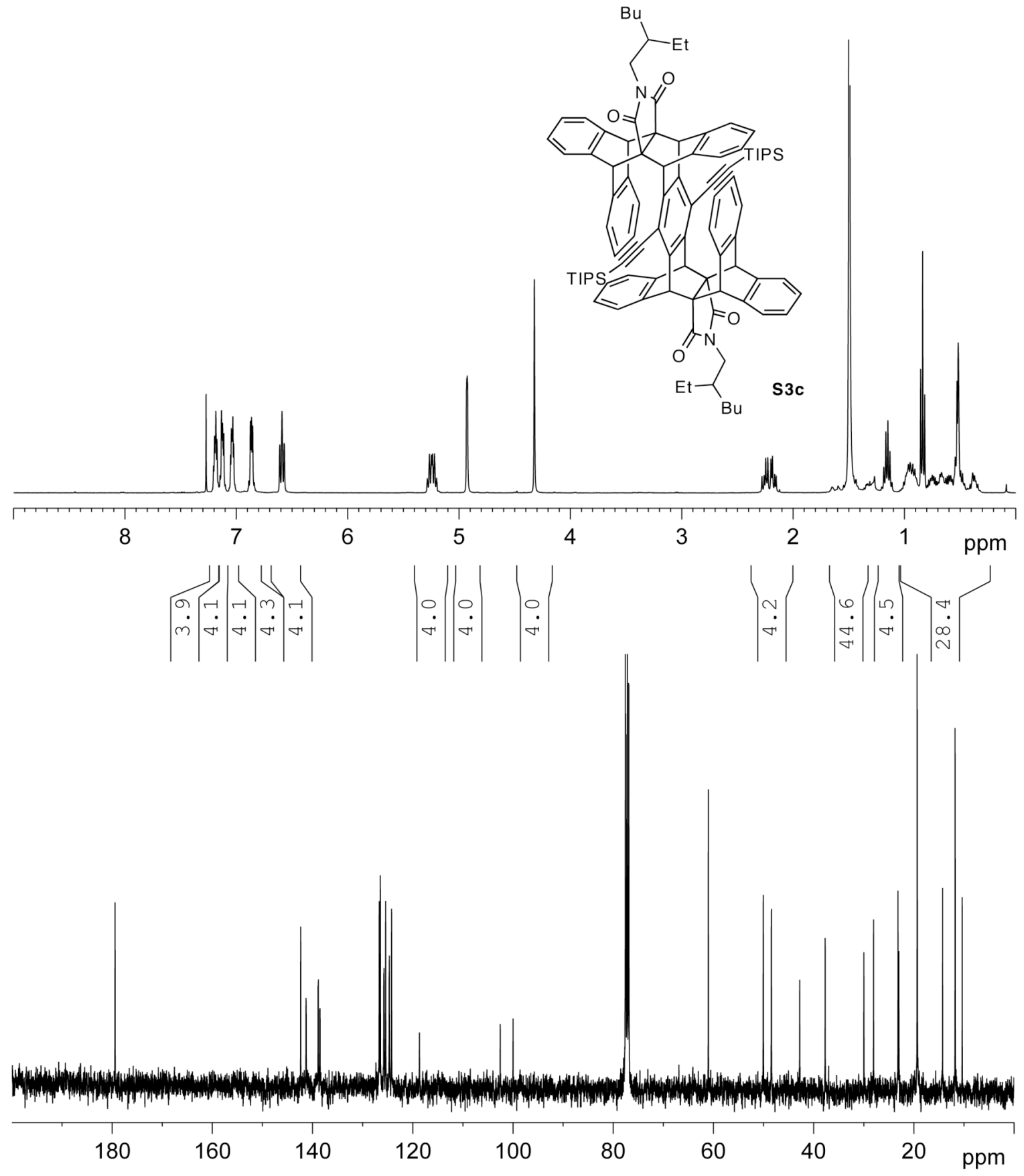

Figure S13. ${ }^{1} \mathrm{H}$ and ${ }^{13} \mathrm{C}$ NMR Spectra of S3c. ${ }^{1} \mathrm{H}$ NMR $\left(400 \mathrm{MHz}, \mathrm{CDCl}_{3}\right) \delta 7.18(\mathrm{~m}, 4 \mathrm{H}), 7.12$ $(\mathrm{m}, 4 \mathrm{H}), 7.04(\mathrm{~m}, 4 \mathrm{H}), 6.86(\mathrm{~m}, 4 \mathrm{H}), 6.59(\mathrm{~m}, 4 \mathrm{H}), 5.24(\mathrm{~m}, 4 \mathrm{H}), 4.93(\mathrm{~s}, 4 \mathrm{H}), 4.32(\mathrm{~s}, 4 \mathrm{H}), 2.21$ $(\mathrm{m}, 4 \mathrm{H}), 1.50(\mathrm{~s}, 42 \mathrm{H}), 1.15-0.84(\mathrm{~m}, 30 \mathrm{H}) .{ }^{13} \mathrm{C} \mathrm{NMR}\left(100 \mathrm{MHz}, \mathrm{CDCl}_{3}\right) \delta 179.42,142.37$, 141.30, 138.90, 138.53, 126.69, 126.46, 125.58 (d, $J=4 \mathrm{~Hz}), 125.42,124.65$ (d, $J=4 \mathrm{~Hz}$ ), 124.23, 118.67, 102.55, 99.99, 61.02, 50.48, 48.44, 42.79, 37.71, 29.98, 28.05, 23.17, 23.00, $19.34,14.27,11.77,10.35$. 


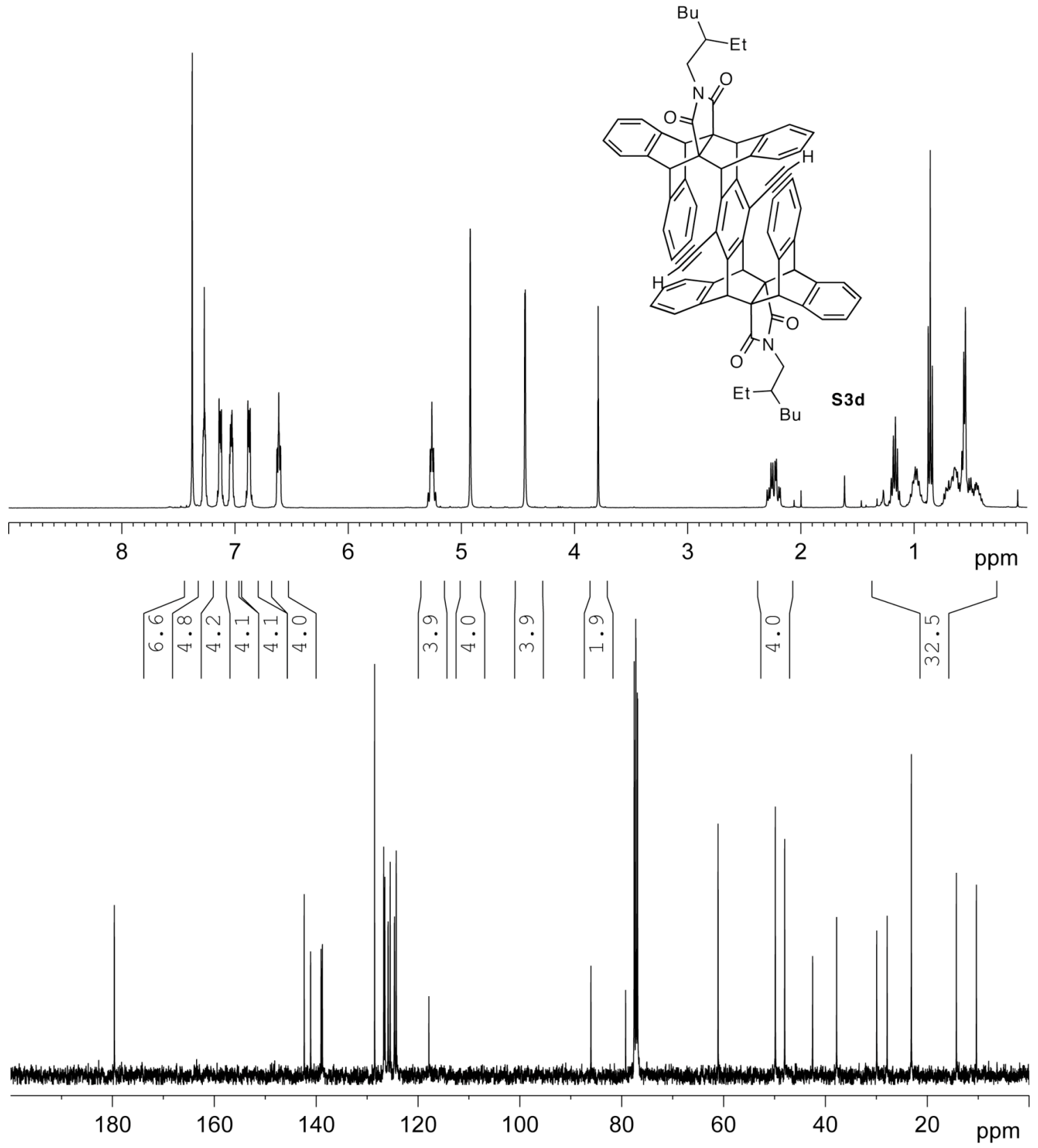

Figure S14. ${ }^{1} \mathrm{H}$ and ${ }^{13} \mathrm{C}$ NMR Spectra of S3d. ${ }^{1} \mathrm{H}$ NMR $\left(400 \mathrm{MHz}, \mathrm{CDCl}_{3}\right) \delta 7.26(\mathrm{~m}, 4 \mathrm{H}), 7.13$ $(\mathrm{m}, 4 \mathrm{H}), 7.04(\mathrm{~m}, 4 \mathrm{H}), 6.87(\mathrm{~m}, 4 \mathrm{H}), 6.61(\mathrm{~m}, 4 \mathrm{H}), 5.26(\mathrm{~m}, 4 \mathrm{H}), 4.92(\mathrm{~s}, 4 \mathrm{H}), 4.37(\mathrm{~s}, 4 \mathrm{H}), 3.79$ $(\mathrm{s}, 2 \mathrm{H}), 2.22(\mathrm{~m}, 4 \mathrm{H}), 1.20-0.88(\mathrm{~m}, 30 \mathrm{H}) .{ }^{13} \mathrm{C}$ NMR $\left(100 \mathrm{MHz}, \mathrm{CDCl}_{3}\right) \delta 179.63,142.34,141.09$, 139.03, 138.77, 128.52, 126.73, 126.51, 125.86 (d, $J=4 \mathrm{~Hz}), 125.46,124.65$ (d, $J=4 \mathrm{~Hz}$ ), 124.27, 117.86, 86.04, 79.23, 61.08, 49.84, 48.01, 42.52, 37.81, 29.94, 27.89, 23.13, 14.29, 10.36 . 


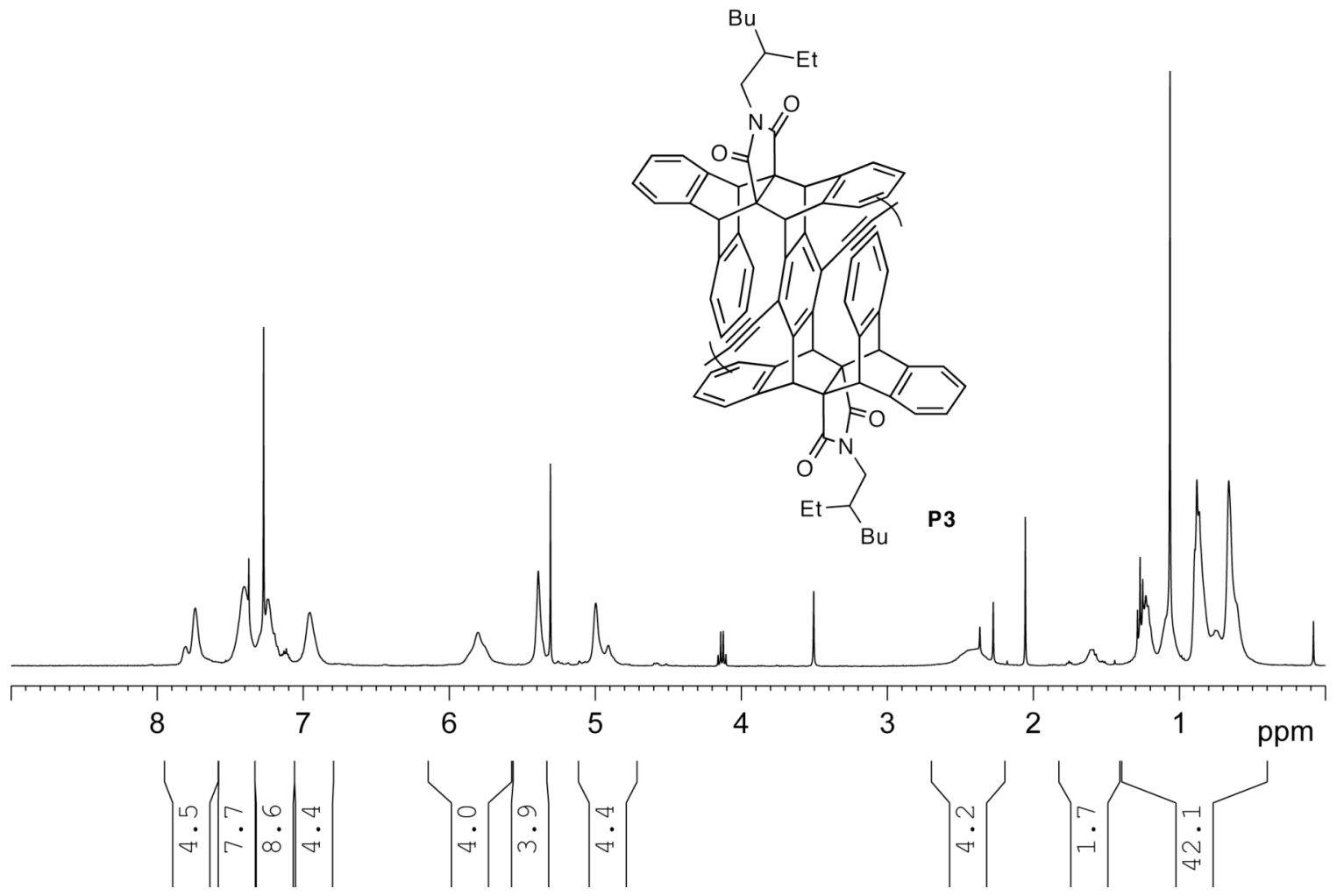

Figure S15. ${ }^{1} \mathrm{H}$ NMR Spectrum of P3. ${ }^{1} \mathrm{H}$ NMR $\left(400 \mathrm{MHz}, \mathrm{CDCl}_{3}\right) \delta 7.74(\mathrm{bm}, 4 \mathrm{H}), 7.40(\mathrm{bm}$, $8 \mathrm{H}), 7.27(\mathrm{bm}, 4 \mathrm{H}), 6.96(\mathrm{bm}, 4 \mathrm{H}), 5.83(\mathrm{bm}, 4 \mathrm{H}), 5.39$ (bs, 4H), 5.00 (bs, 4H), $2.44(\mathrm{bm}, 4 \mathrm{H})$, $1.29-0.66(\mathrm{~m}, 30 \mathrm{H})$. 


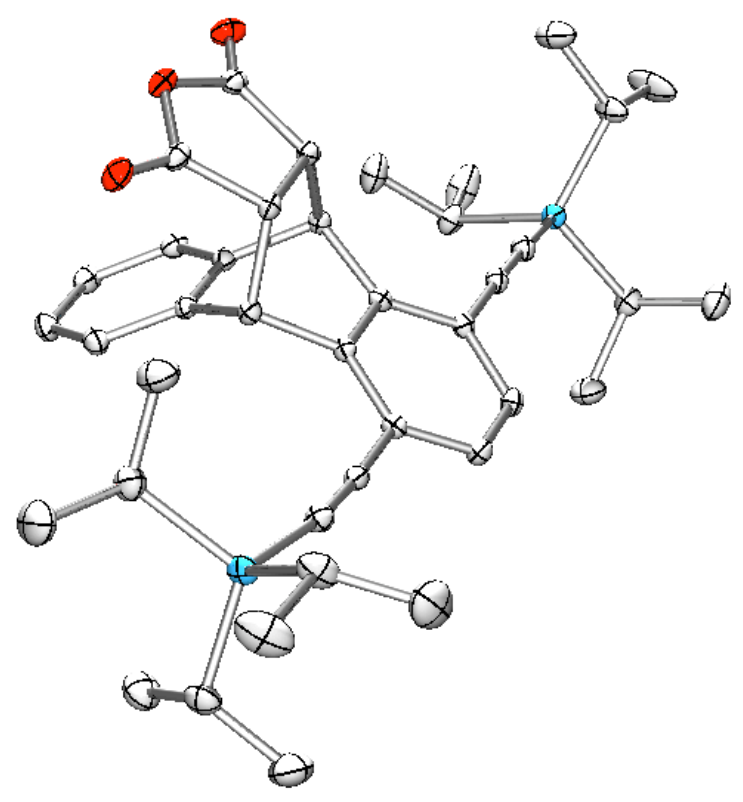

Figure S16. X-ray crystal structure of $\mathbf{S} 1 \mathbf{b} .^{8}$ Suitable crystals were grown using hot $\mathrm{CH}_{3} \mathrm{CN}$ benzene solutions followed by slow solvent evaporation overnight. 


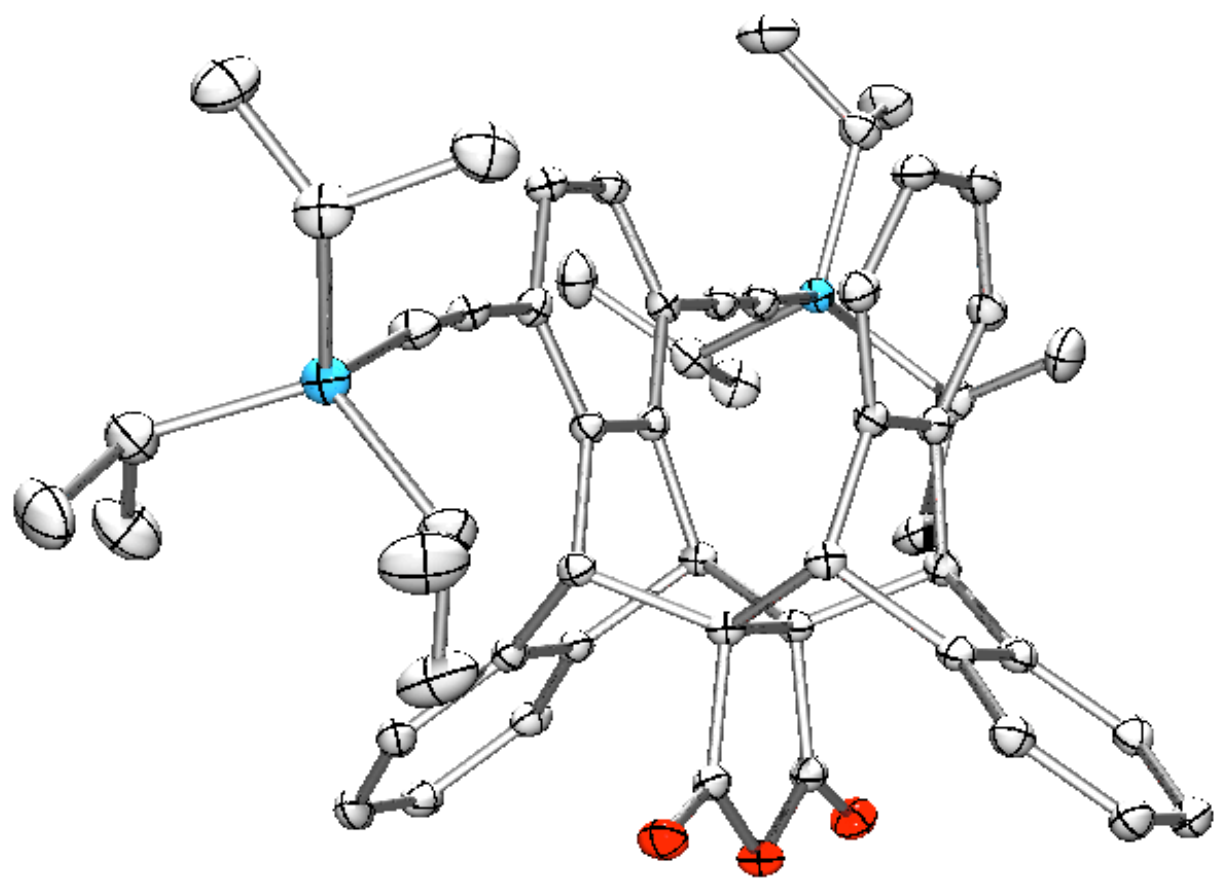

Figure S17. X-ray crystal structure of S2b. Suitable crystals were grown using hot $\mathrm{CH}_{3} \mathrm{CN}$ benzene solutions followed by slow solvent evaporation overnight.

Table S1. Summary of Bond Distances and Angles for S2b.

\begin{tabular}{cc}
\hline centroid distance & $3.444 \AA$ \\
\hline angle between the planes of rings & $18.19 \pm 0.03$ \\
\hline shortest intermolecular C-C arene-arene distance & $3.007 \AA$ \\
\hline middle intermolecular C-C arene-arene distance & $3.380 \AA$ \\
\hline farthest intermolecular C-C arene-arene distance & $3.842 \AA$ \\
\hline
\end{tabular}




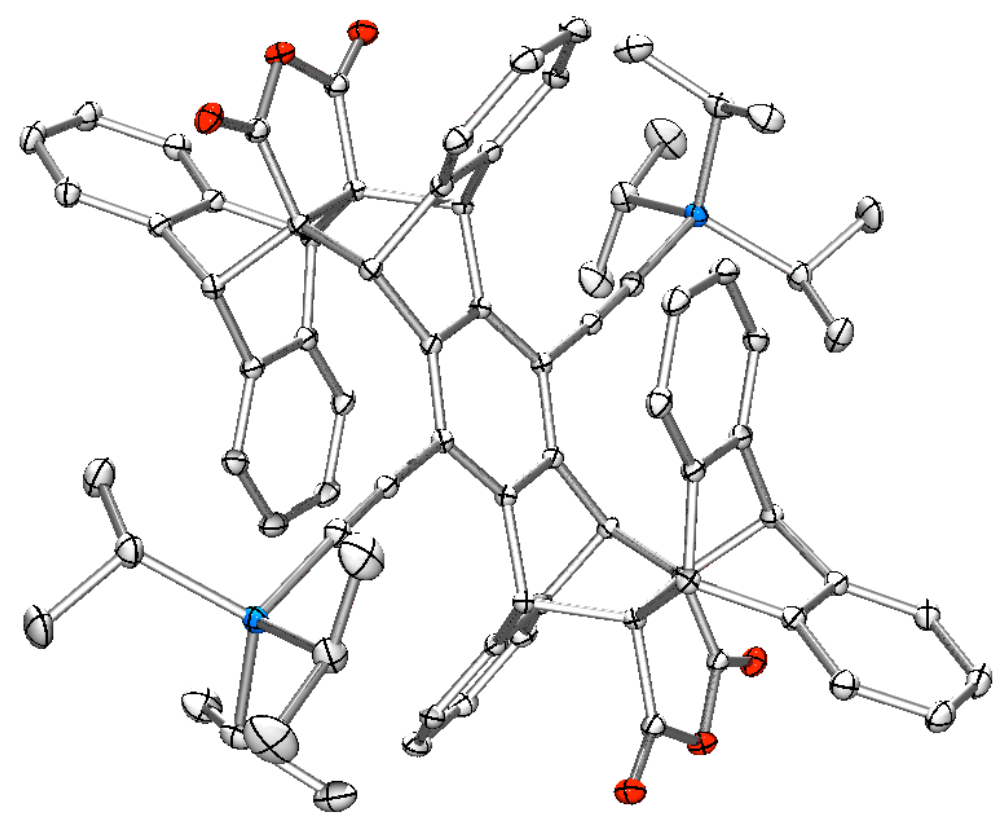

Figure S18. X-ray crystal structure of S3b. Suitable crystals were grown starting with hot $\mathrm{CHCl}_{3}$ benzene solutions followed by slow solvent evaporation overnight. For clarity, the disordered $\mathrm{CHCl}_{3}$ (solvent) molecule was omitted.

Table S2. Summary of Bond Distances and Angles for S3b.

\begin{tabular}{cc}
\hline centroid distance & $3.442 \AA$ \\
\hline angle between the planes of rings & $17.67 \pm 0.05$ \\
\hline shortest intermolecular C-C arene-arene distance & $3.007 \AA$ \\
\hline middle intermolecular C-C arene-arene distance & $3.419 \AA$ \\
\hline farthest intermolecular C-C arene-arene distance & $3.837 \AA$ \\
\hline
\end{tabular}




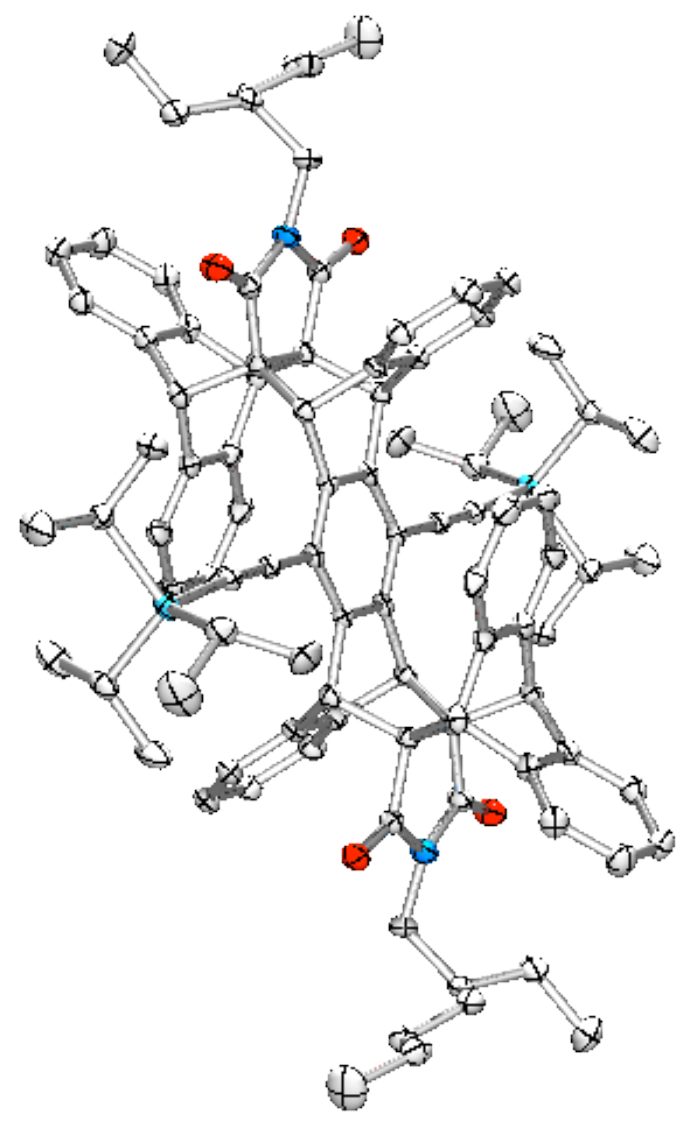

Figure S19. X-ray crystal structure of S3c. Suitable crystals were grown using hot $\mathrm{CHCl}_{3}$ benzene solutions followed by slow solvent evaporation overnight. Both the TIPS group and the $\mathrm{N}$-alkyl chains showed disorder in the structure, however, these features are omitted from this ORTEP for clarity.

Table S3. Summary of Bond Distances and Angles for S3c.

\begin{tabular}{cc}
\hline centroid distance & $3.371 \AA$ \\
\hline angle between the planes of rings & $16.85 \pm 0.05$ \\
\hline shortest intermolecular C-C arene-arene distance & $2.977 \AA$ \\
\hline middle intermolecular C-C arene-arene distance & $3.349 \AA$ \\
\hline farthest intermolecular C-C arene-arene distance & $3.751 \AA$ \\
\hline
\end{tabular}




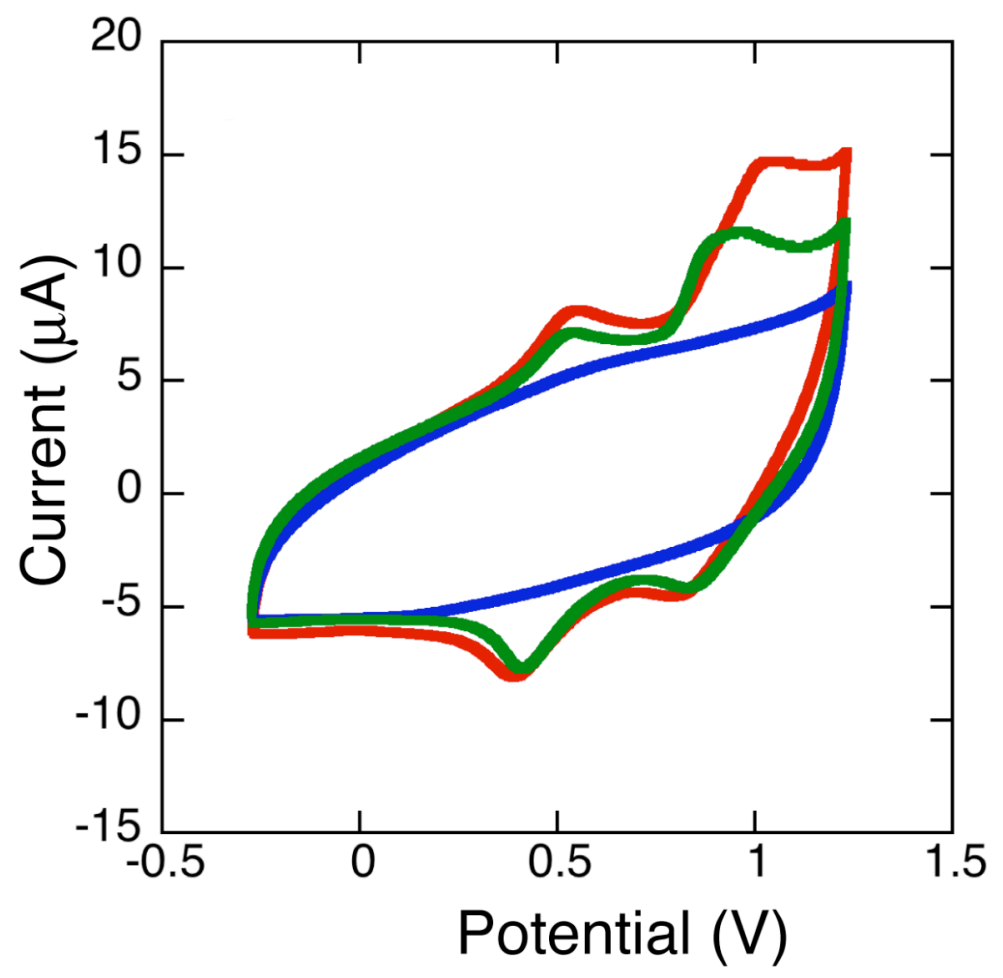

Figure S20. CV Scans for S1b (blue), S2b (green), S3b (red). Conditions: scan rate $=500$ $\mathrm{mV} / \mathrm{s}$, concentration $=\sim 1 \times 10^{-2} \mathrm{M}$, solvent $=\mathrm{CH}_{2} \mathrm{Cl}_{2} / 0.1 \mathrm{M} \mathrm{TBAPF}_{6}$, working electrode $=$ glassy carbon.

Table S4. Summary of Oxidation Potentials.

\begin{tabular}{cccc}
\hline Cmpd & vs $\mathrm{Ag} / \mathrm{AgNO}_{3}$ (V) & vs Fc/Fc & \\
\hline S1b & -- & -- & vs SHE (V) \\
\hline S2b & $0.701,1.123$ & $0.476,0.898$ & -- \\
\hline S3b & $0.696,1.148$ & $0.471,0.923$ & $1.231,1.653$ \\
\hline
\end{tabular}




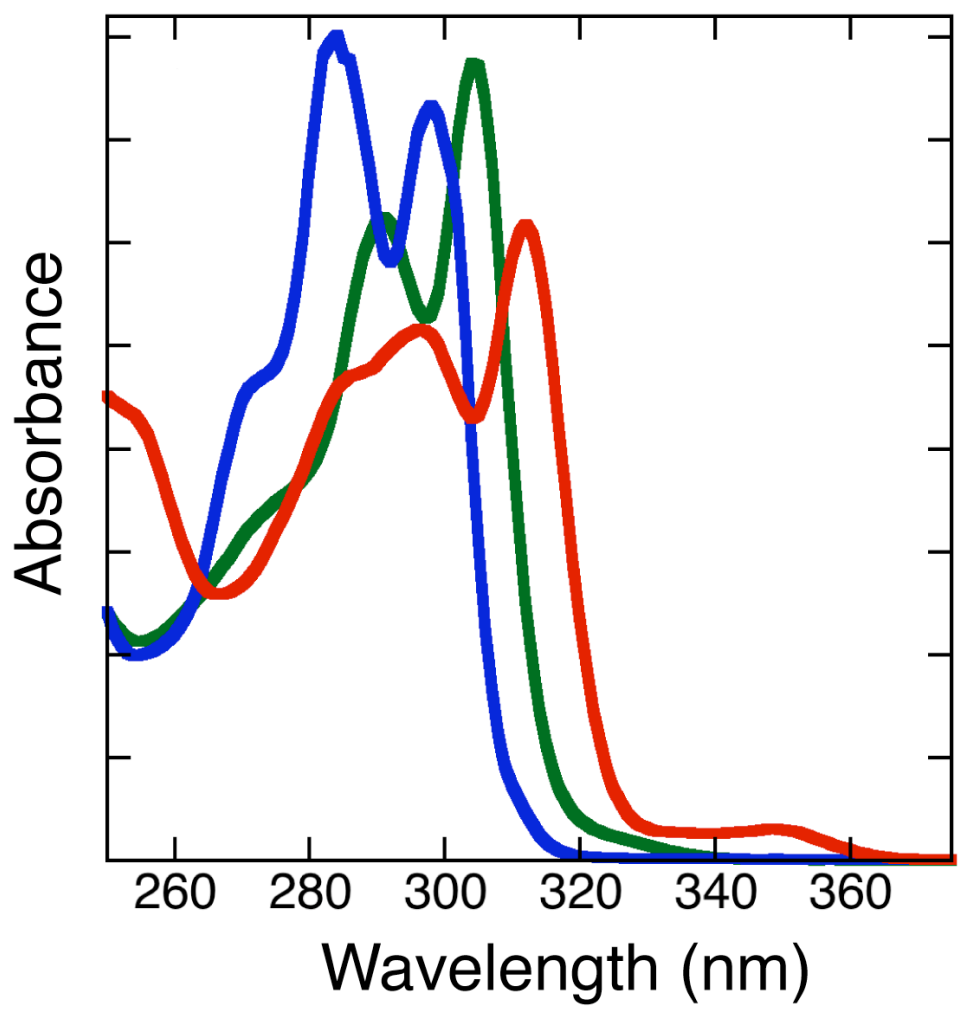

Figure S21. Absorption spectra for $\mathbf{S 1 b}$ (blue), $\mathbf{S 2 b}$ (green), and $\mathbf{S} 3 \mathbf{b}$ (red) acquired in $\mathrm{CHCl}_{3}(\sim$ $\left.1 \times 10^{-4} \mathrm{M}\right)$.

Table S5. Summary of Spectral Data for Figure S22.

\begin{tabular}{cccc}
\hline Cmpd & $\lambda_{\max }(\mathbf{n m})$ & $\log \boldsymbol{\varepsilon}$ & $\mathbf{E}_{\mathbf{g}}(\mathbf{e V})^{a}$ \\
\hline S1b & 284 & 4.51 & 3.94 \\
\hline S2b & 304 & 4.58 & 3.81 \\
\hline S3b & 312 & 4.48 & $3.76^{b}$ \\
\hline
\end{tabular}

${ }^{a}$ The HOMO-LUMO gap is estimated by the onset of absorption. ${ }^{b}$ This value did not include the small absorption at $350 \mathrm{~nm}$, tentatively assigned to a charge-transfer interaction. 

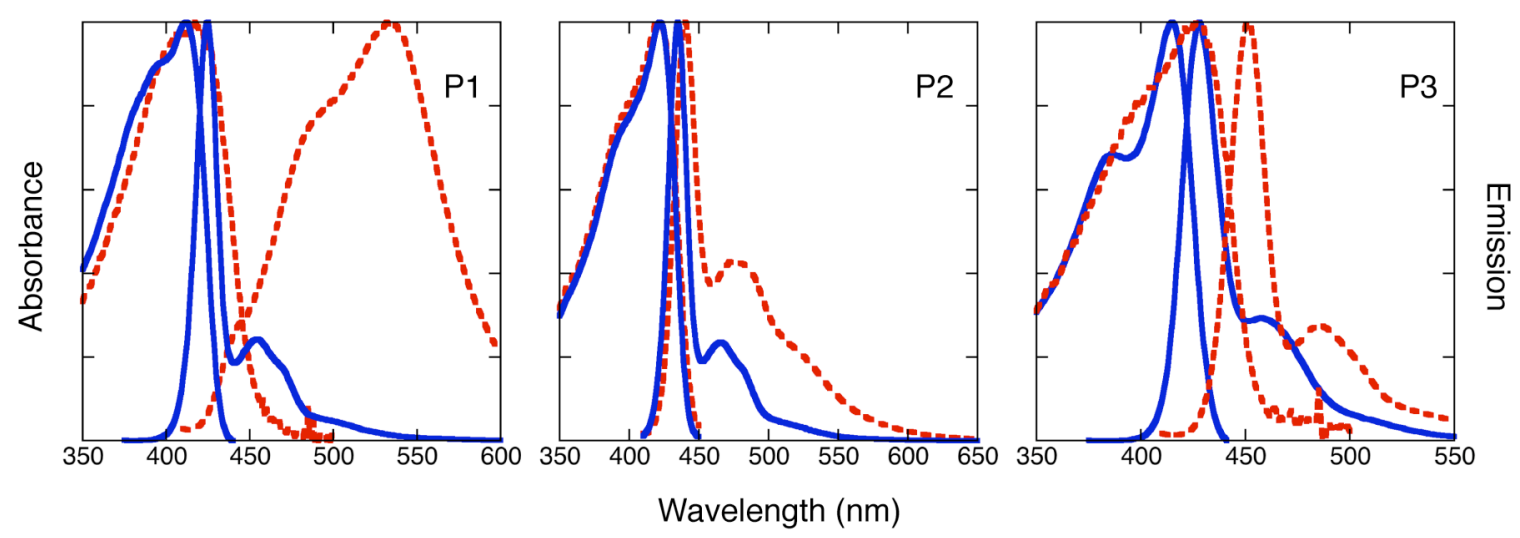

Figure S22. Absorption and emission spectra for $\mathbf{P 1}, \mathbf{P} 2$, and $\mathbf{P} 3$ acquired in $\mathrm{CHCl}_{3}$ (blue/solid) or as thin films on glass slides (red/dashed).

Table S6. Summary of Spectral Data for Figure S22.

\begin{tabular}{cccccc}
\hline & \multicolumn{2}{c}{ Solution $\left(\mathbf{C H C l}_{3}\right)$} & \multicolumn{2}{c}{ Film } \\
\hline Polymer & $\mathbf{A b s} \lambda_{\max }(\mathbf{n m})$ & $\mathbf{E m} \boldsymbol{\lambda}_{\max }(\mathbf{n m})$ & $\boldsymbol{\Phi}_{\mathrm{F}}$ & $\mathbf{A b s} \lambda_{\max }(\mathbf{n m})$ & $\mathbf{E m} \boldsymbol{\lambda}_{\max }(\mathbf{n m})$ \\
\hline P1 & 412 & 425 & 0.59 & 417 & 533 \\
\hline P1b & 421 & 430 & -- & 417 & 434 \\
\hline P2 & 425 & 435 & 0.67 & 421 & 439 \\
\hline P3 & 415 & 428 & 0.37 & 429 & 450 \\
\hline
\end{tabular}



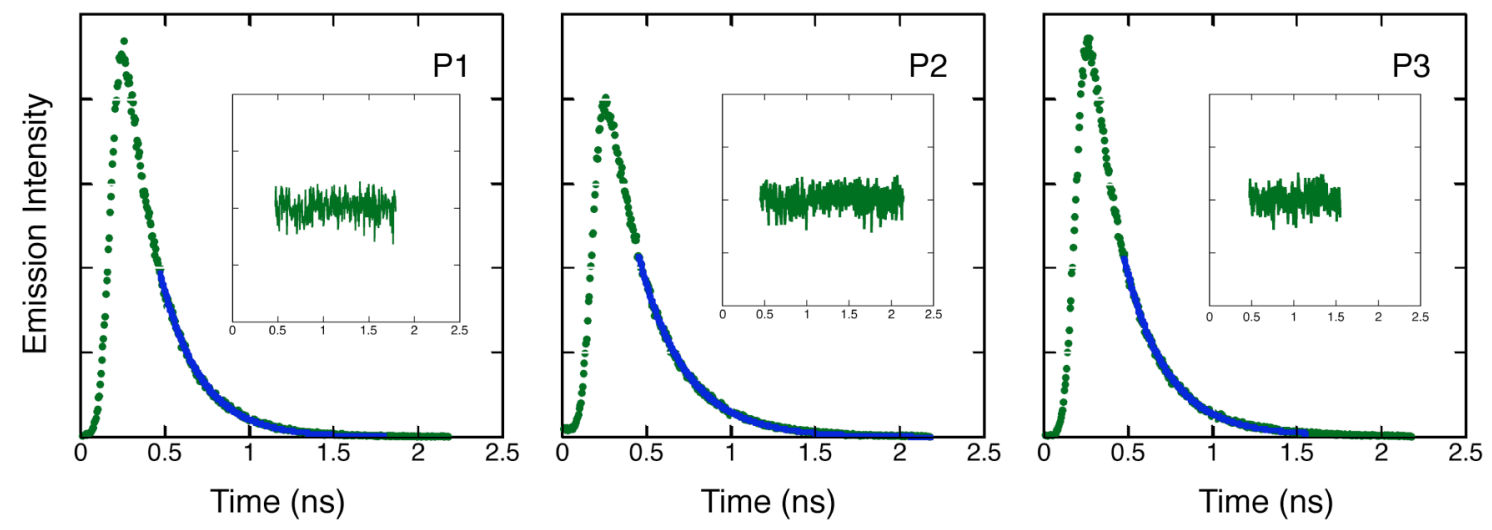

Figure S23. Representative lifetime plots for $\mathbf{P 1}, \mathbf{P 2}$, and $\mathbf{P} 3$ in $\mathrm{CHCl}_{3}$ solution. The blue line represents the best-fit curve and the inset shows the residuals.
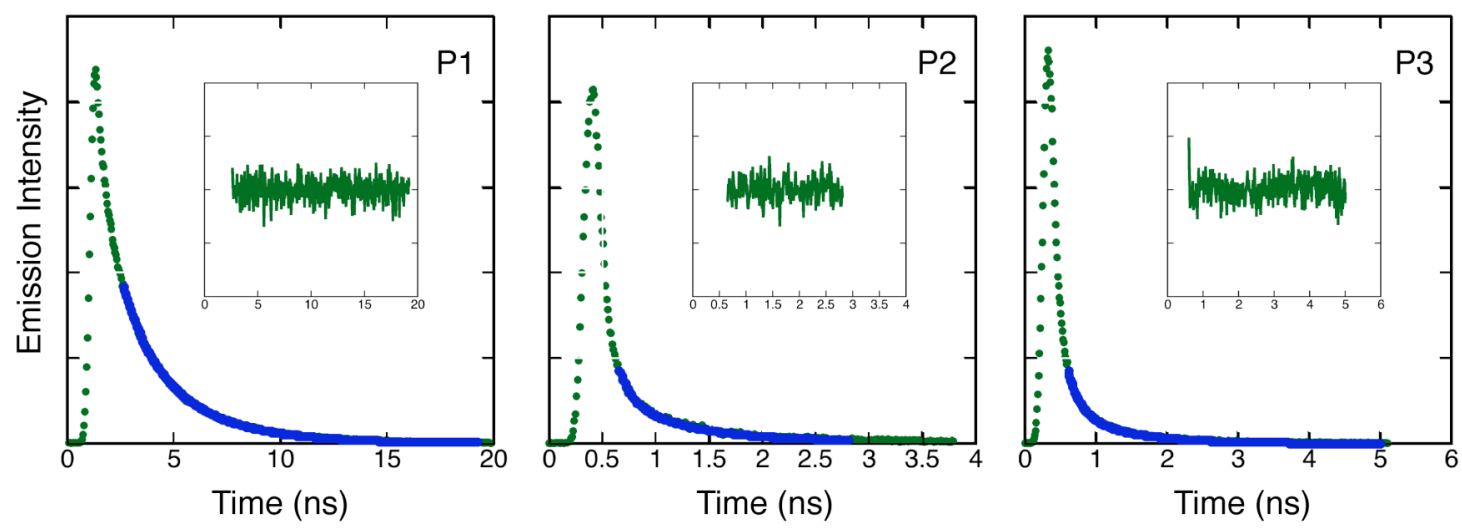

Figure S24. Representative lifetime plots for P1, P2, and P3 acquired for thin films on glass slides. The blue line represents the best-fit curve and the inset shows the residuals.

Table S7. Summary of Averaged Lifetimes in Solution and Films (Figures S23-S24).

\begin{tabular}{ccc}
\hline Polymer & $\boldsymbol{\tau}_{\text {soln }}(\mathbf{n s})$ & $\boldsymbol{\tau}_{\text {filn }}(\mathbf{n s})$ \\
\hline P1 & 0.24 & $1.30(63 \%), 3.19(37 \%)$ \\
\hline P2 & 0.27 & $0.13(96 \%), 0.63(4 \%)$ \\
\hline P3 & 0.25 & $0.12(98 \%), 0.67(2 \%)$ \\
\hline
\end{tabular}


a. Calculated Geometry

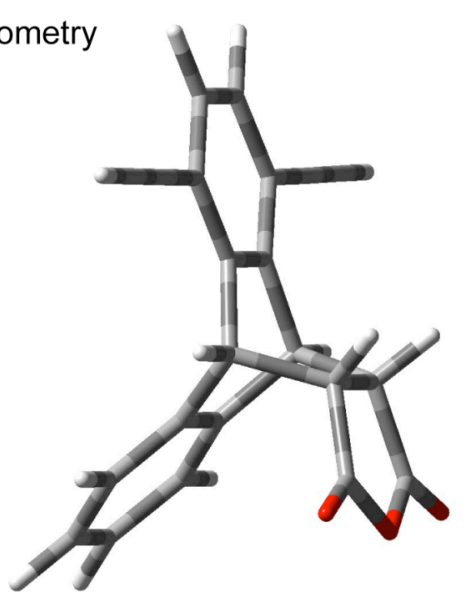

b. HOMO

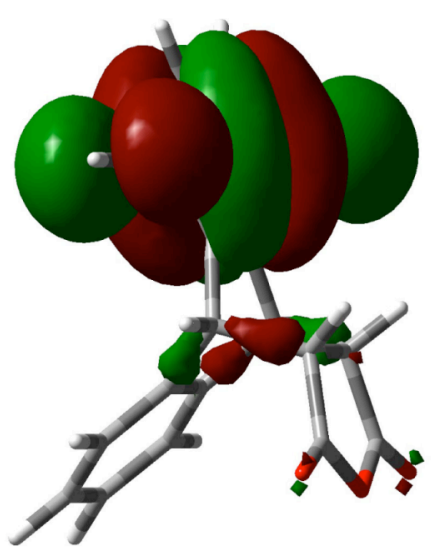

c. LUMO

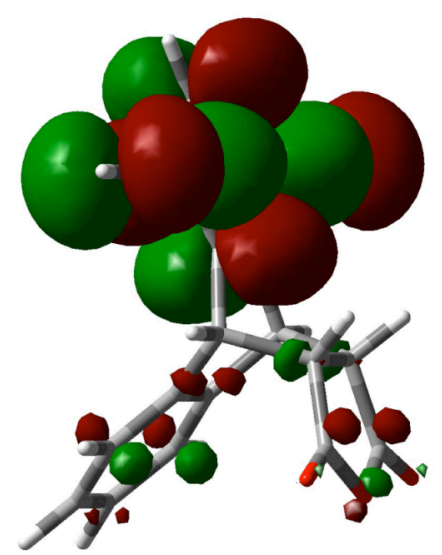

Figure S25. Results for geometry minimization and single-point energy calculation using B3LYP/6-31G(d) on S1b: (a) optimized geometry, (b) HOMO, (c) LUMO. ${ }^{9}$ 


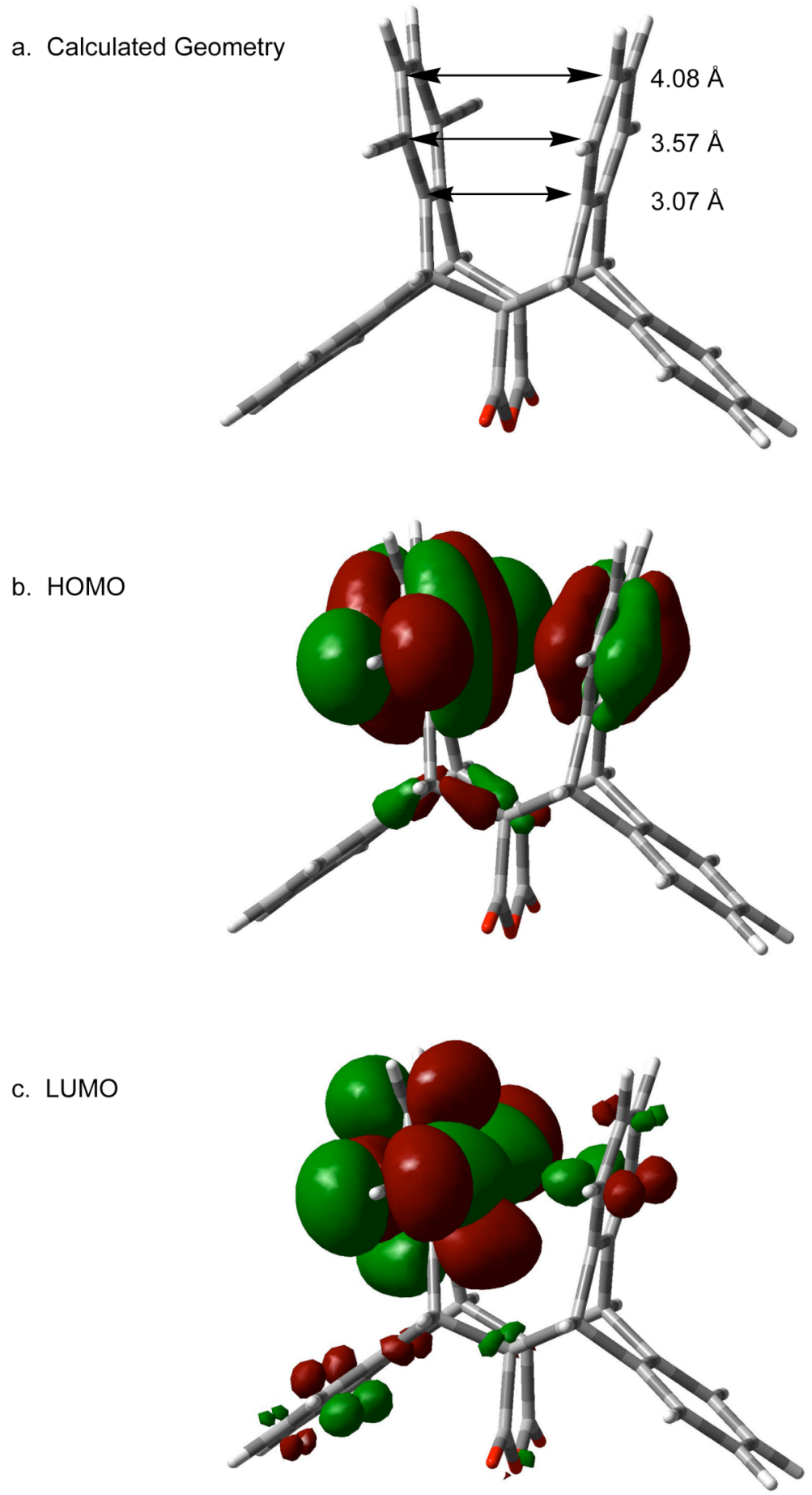

Figure S26. Results for geometry minimization and single-point energy calculation using B3LYP/6-31G(d) on S2b: (a) optimized geometry, (b) HOMO, (c) LUMO. 
a. Calculated Geometry

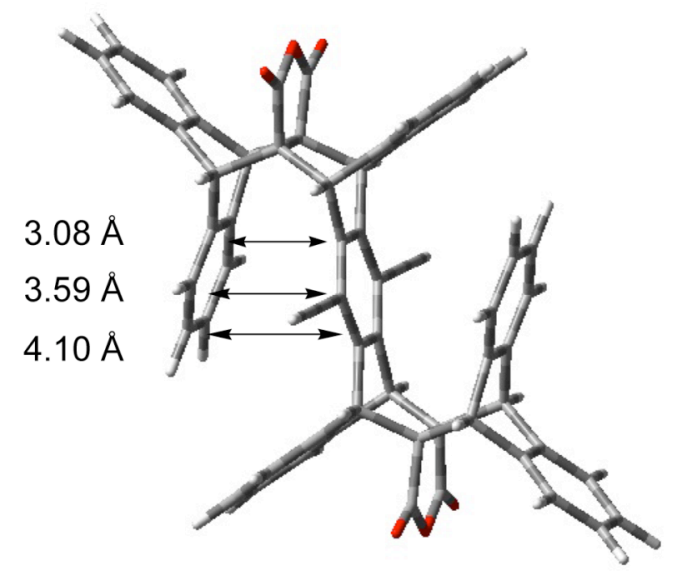

b. HOMO

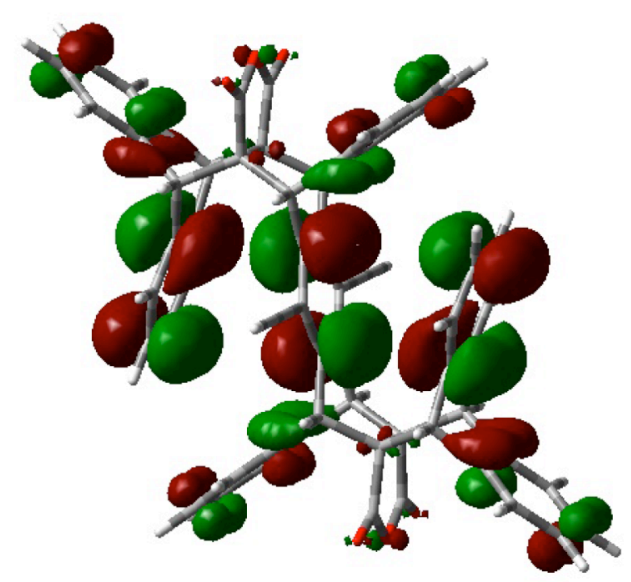

c. LUMO

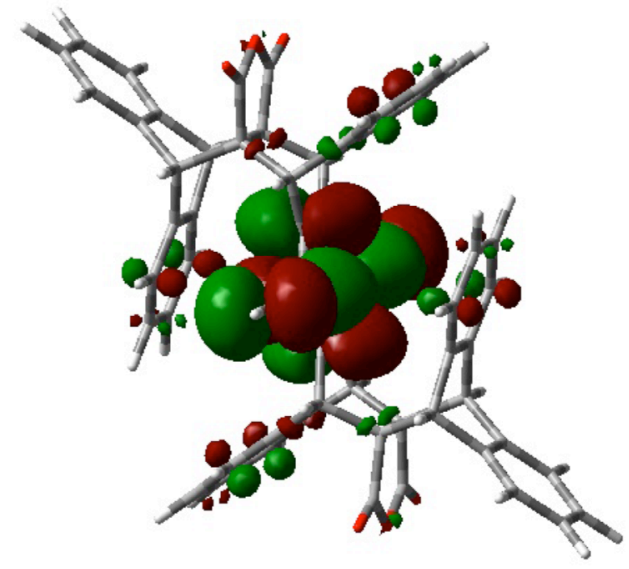

Figure S27. Results for geometry minimization and single-point energy calculation using B3LYP/6-31G(d) on S3b: (a) optimized geometry, (b) HOMO, (c) LUMO. 
a. Structure

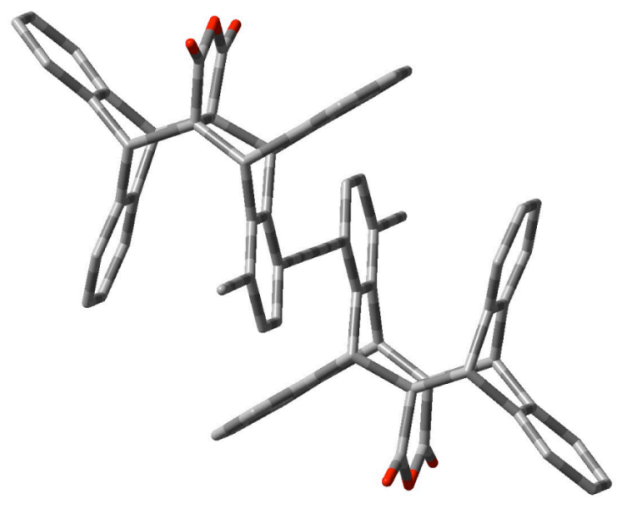

b. HOMO

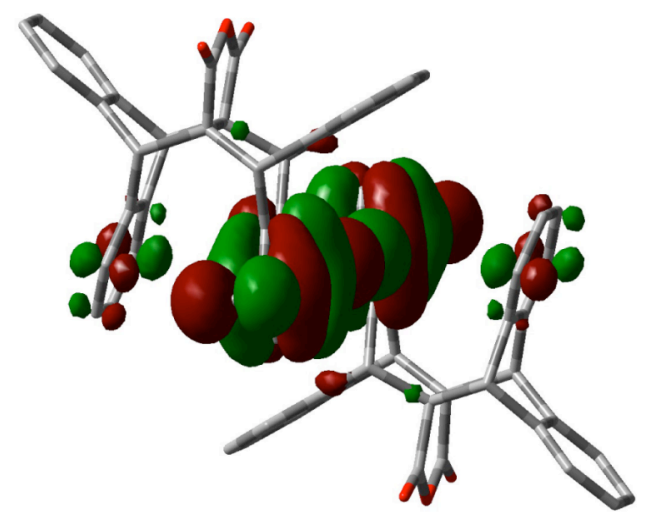

c. LUMO

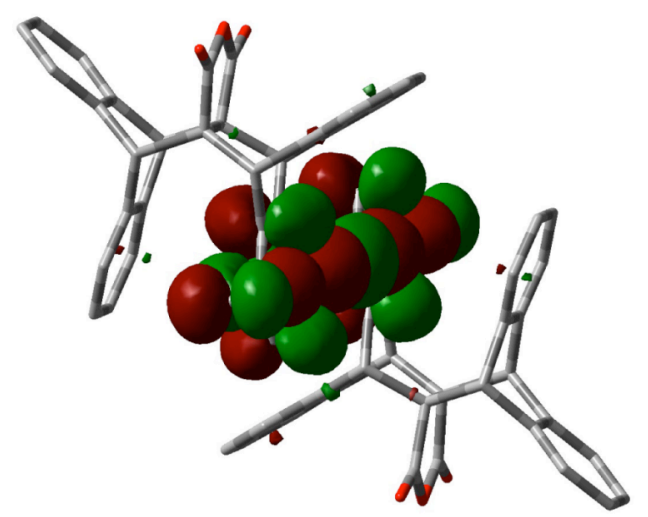

Figure S28. Results for single-point energy calculation using B3LYP/6-31G(d) on S2b-S2b dimer (made using the geometry-optimized monomer): (a) structure, (b) HOMO, (c) LUMO. 
a. Structure

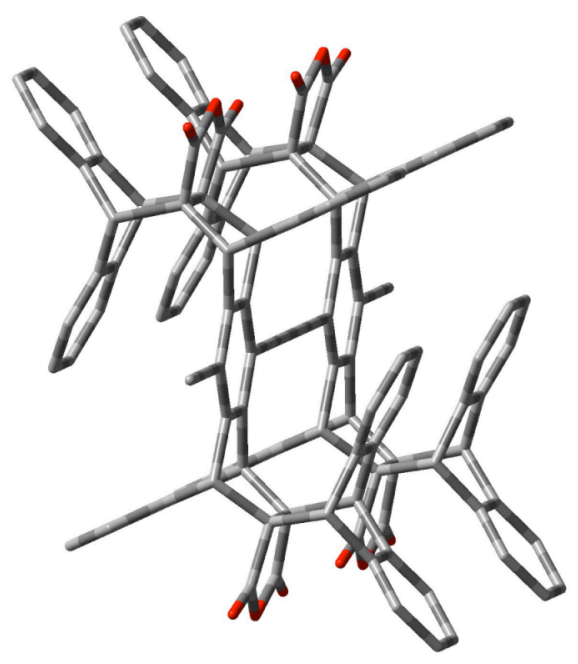

b. HOMO

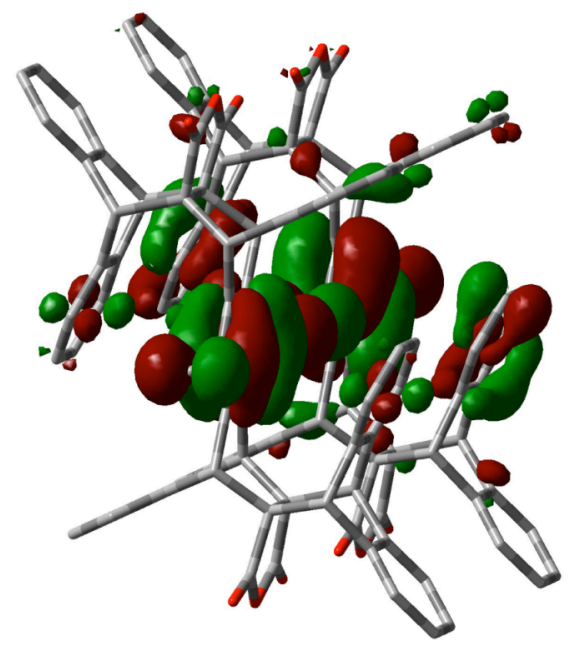

c. LUMO

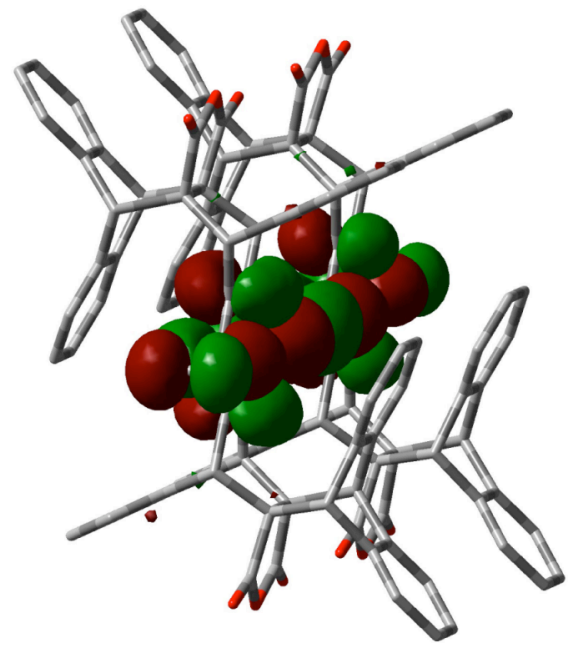

Figure S29. Results for a single-point energy calculation using B3LYP/6-31G(d) on S3b-S3b dimer (made using the geometry-optimized monomer): (a) structure, (b) HOMO, (c) LUMO. 

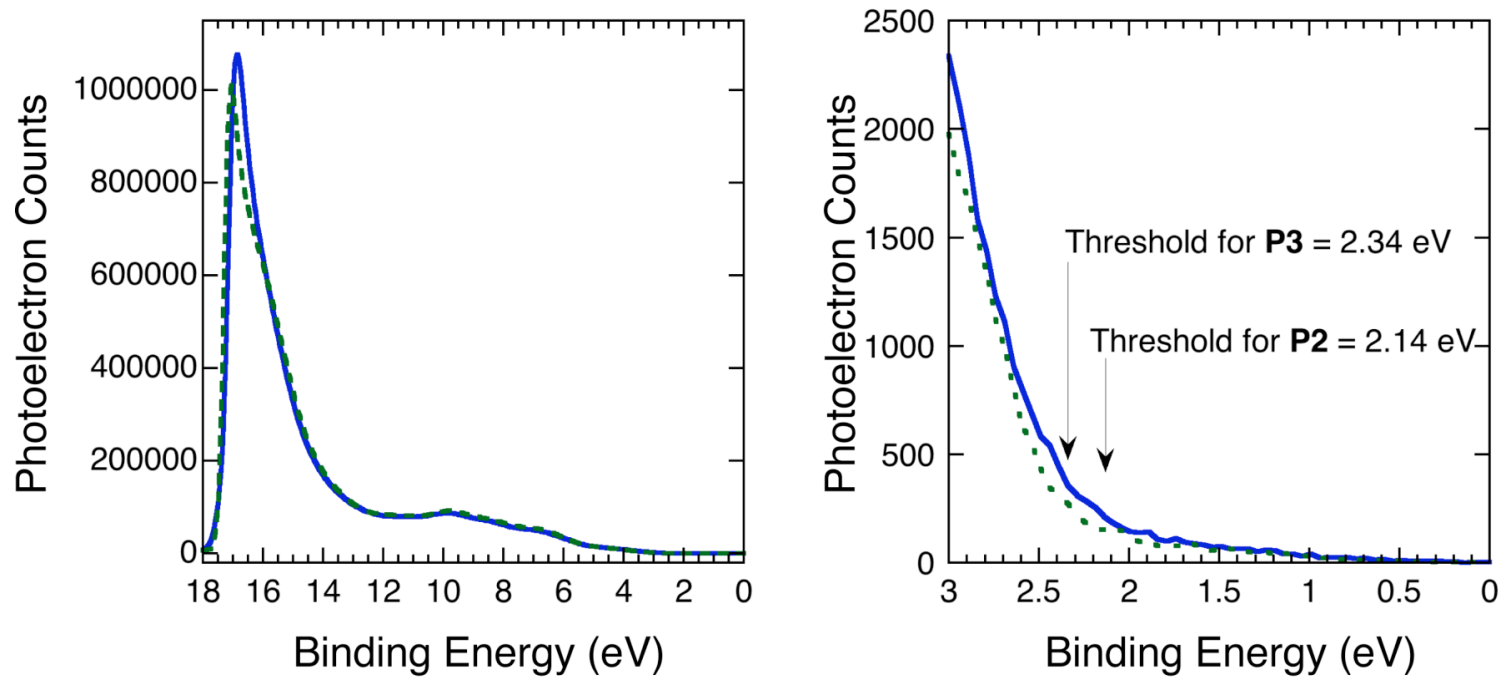

Figure S30. UPS spectra for thin films of P2 (blue/solid) and P3 (green/dashed) spin-coated onto gold substrates at a concentration of $4 \mathrm{mg} / \mathrm{mL}\left(\mathrm{CHCl}_{3}\right)$.

Table S8. Data for Figure S30.

\begin{tabular}{cccc}
\hline Polymer & $\begin{array}{c}\text { Secondary } \\
\text { Electron Cutoff }\end{array}$ & Threshold $(\mathbf{e V})$ & IP (eV) \\
\hline P1 & -- & -- & \\
\hline P2 & 17.61 & 2.14 & 5.75 \\
\hline P3 & 17.56 & 2.34 & 6.00 \\
\hline
\end{tabular}



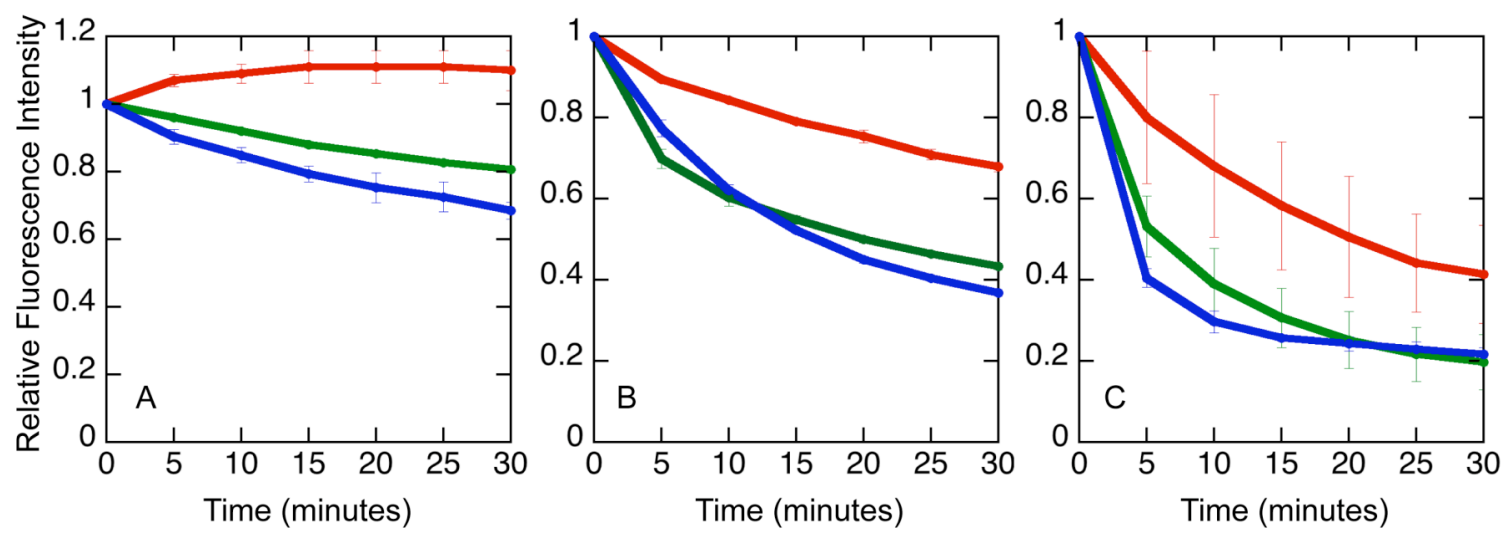

Figure S31. Relative fluorescence intensity versus time for polymer thin films [P1 (blue); P2 (green); and P3 (red)] under continuous irradiation at $400 \mathrm{~nm}(\mathrm{OD}=0.035 \pm 0.005)$. The excitation slit widths were varied: (A) $2.5 \mathrm{~nm}$; (B) $5 \mathrm{~nm}$; (C) $15 \mathrm{~nm}$. 


\section{References}

(1) Demmig, S., Langhals, H. Chem. Ber. 1988, 121, 225-230.

(2) Sheldrick, G. M. Acta Cryst. Sect. A 1990, 46, 467.

(3) Sheldrick, G. M. SHELXL 97, Universität Göttingen, Germany, 1997.

(4) (a) Salaneck, W. R.; Stafström, S.; Brédas, J. L. Conjugated Polymer Surfaces and Interfaces: Electronic and Chemical Structure of Interfaces for Polymer Light Emitting Devices; Cambridge University Press: Cambridge, 1996. (b) Salaneck, W. R.; Lögdlund, M.; Fahlman, M.; Greczynski, G.; Kugler, Th. Mater. Sci. Eng. R 2001, 34, 121-146. (c) Liao, L.-S.; Lee, C. S.; Lee, S. T.; Inbasekaran, M.; Wu, W. W. In Conjugated Polymer and Molecular Interfaces: Science and Technology for Photonic and Optoelectronic Applications; Salaneck, W. R., Seki, K., Kahn, A., Pireaux, J.-J., Eds; Marcel Dekker: New York, 2002; 401-441.

(5) Landis, C. A.; Parkin, S. R.; Anthony, J. E. Jap. J. Appl. Phys. 2005, 44, 3921-3922.

(6) The observed anti selectivity was postulated to result from a charge transfer complex forming prior to the Diels-Alder reaction. Kitamura, C.; Hasegawa, M.; Ishikawa, H.; Fujimoto, J.; Ouchi, M.; Yoneda, A. Bull. Chem. Soc. Jpn. 2004, 77, 1385-1393.

(7) Kim, Y.; Whitten, J. E.; Swager, T. M. J. Am. Chem. Soc. 2005, 127, 12122-12130.

(8) All crystal structure images were created using Pov-Ray ${ }^{\mathrm{TM}}$, The Persistence of Vision Raytracer $^{\mathrm{TM}}$, a freeware program found on the web at www.povray.org.

(9) Gaussian 03, Revision C.02. M. J. Frisch, G. W. Trucks, H. B. Schlegel, G. E. Scuseria, M. A. Robb, J. R. Cheeseman, J. A. Montgomery, Jr., T. Vreven, K. N. Kudin, J. C. Burant, J. M. Millam, S. S. lyengar, J. Tomasi, V. Barone, B. Mennucci, M. Cossi, G. Scalmani, N. Rega, G. A. Petersson, H. Nakatsuji, M. Hada, M. Ehara, K. Toyota, R. Fukuda, J. Hasegawa, M. Ishida, T. Nakajima, Y. Honda, O. Kitao, H. Nakai, M. Klene, X. Li, J. E. Knox, H. P. Hratchian, J. B. Cross, C. Adamo, J. Jaramillo, R. Gomperts, R. E. Stratmann, O. Yazyev, A. J. Austin, R. Cammi, C. Pomelli, J. W. Ochterski, P. Y. Ayala, K. Morokuma, G. A. Voth, P. Salvador, J. J. Dannenberg, V. G. Zakrzewski, S. Dapprich, A. D. Daniels, M. C. Strain, O. Farkas, D. K. Malick, A. D. Rabuck, K. Raghavachari, J. B. Foresman, J. V. Ortiz, Q. Cui, A. G. Baboul, S. Clifford, J. Cioslowski, B. B. Stefanov, G. Liu, A. Liashenko, P. Piskorz, I. Komaromi, R. L. Martin, D. J. Fox, T. Keith, M. A. AlLaham, C. Y. Peng, A. Nanayakkara, M. Challacombe, P. M. W. Gill, B. Johnson, W. Chen, M. W. Wong, C. Gonzalez, and J. A. Pople, Gaussian, Inc., Wallingford CT, 2004. 